\title{
LA INSTITUCIÓN TERESIANA DURANTE LA DICTADURA DE PRIMO DE RIVERA. UNA APROXIMACIÓN A SU PROYECCIÓN EDUCATIVA, SOCIAL Y PÚBLICA
}

\author{
POR
}

Francisca RosiQue Navarro

Cátedra de Historia de la Institución Teresiana

María Dolores Peralta Ortiz

Universidad Pontificia Comillas de Madrid

\section{RESUMEN}

Un grupo poco estudiado en los años 20 del pasado siglo a pesar de su influencia no solo en el ámbito educativo sino también en el cultural y público, es la Institución Teresiana, fundada por el sacerdote Pedro Poveda en 1911. Este grupo de mujeres católicas -entre las que destacan María de Echarri, Carmen Cuesta y Josefa Segovia-, destacan por constituir un núcleo de mujeres preparadas y empeñadas en recristianizar la sociedad española de estos años en medio de la dura confrontación catolicismo-laicismo. Buena parte de ellas habían obtenido sus títulos en la Escuela Superior de Magisterio y ejercían su profesión como profesoras de escuelas normales e inspectoras. La colaboración con la naciente Acción Católica de la Mujer, la participación en el Primer Congreso Nacional de Educación Católica así como sus propias actividades, dan cuenta de la significatividad de estas mujeres católicas en la vida social, política y sobre todo educativa de la España de esos años.

Palabras ClaVE: España. Primo de Rivera, mujeres, educación, Catolicismo, Institución Teresiana 


\title{
THE TERESIAN INSTITUTE DURING THE DICTATORSHIP OF PRIMO DE RIVERA. AN APPROXIMATION TO ITS EDUCATIONAL, SOCIAL AND PUBLIC PROJECTION
}

\begin{abstract}
Despite its influence the Teresian Institute, founded by the priest Pedro Poveda in 1911, was little studied during the 1920s, not only educationally but also within its cultural and public scope. This group of catholic women -highlighting María de Echarri, Carmen Cuesta and Josefa Segovia- stand out by constituting a nucleus of women who were prepared and committed to re-Christian Spanish society at the time in the midst of a strong catholic-secular confrontation. A large number of them had obtained their degrees in the official Teachers' Training College and carried out their professions as teachers in ordinary schools and as inspectors.

Their collaboration with the rising Catholic Action for Women, their participation in the first National Congress of Catholic Education together with their own activities, show the significance of these catholic women in the social and political life but especially within the educational field in Spain during those years.
\end{abstract}

KEY WORDS: Spain, Primo de Rivera, women, education, Catholicism, Teresian Institute

Recibido/Received 2011-01-15

Aceptado/Accepted 2011-06-07

Tras una breve presentación de la Institución Teresiana en general y la evolución de las Academias teresianas que la originaron, presentamos en estas páginas una aproximación a la vida de esta asociación en los años de la dictadura de Primo de Rivera.

Nuestra «aproximación» no puede dejar de ser lo que anuncia. Algunas cuestiones serán más nombradas que analizadas, dado el estado inicial de los estudios, y nuestro análisis se ceñirá a tres ámbitos especialmente relacionados con los fines de la Institución Teresiana y las oportunidades que brindaba la coyuntura primorriverista para la mujer católica: La relación de la Institución Teresiana con la naciente Asociación Católica de la Mujer y la presencia de algunas de sus líderes más caracterizadas. La proyección educativa, especialmente a través de la Asociación de las Cooperadoras Técnicas, y la participación en acontecimientos como el Primer Congreso Nacional de Educación Católica (abril de 1924). $\mathrm{Su}$ influencia en la vida cultural, social y pública, a través de los miembros que formaban parte de concejalías y de la Asamblea Nacional.

LA INSTITUCIÓN TERESIANA EN 1924 Y LA EVOLUCIÓN DE LAS ACADEMIAS TERESIANAS

En septiembre de 1924, la Institución Teresiana cuenta con apenas trece años de vida. Su origen y evolución hasta ese momento han ido al hilo de la vida es- 
pañola y eclesial tan peculiar en los comienzos del siglo XX: regeneracionismo, cuestión social, «cuestión escolar», etc.

La situación política española cambió radicalmente el 13 de septiembre de 1923 con el golpe del general Primo de Rivera acogido positivamente por los partidos políticos, tanto de derecha como de izquierda, por los obispos y por la mayoría de los españoles. ${ }^{1}$ Hay quien piensa que a los obispos el modelo autoritario les parecía más apto para defender los valores católicos, aunque para otros esta impresión requiere matizaciones. ${ }^{2}$

En el ámbito educativo Primo de Rivera cedió buena parte de la responsabilidad del control ideológico a la Iglesia Católica para penalizar las doctrinas ofensivas a la religión. Al menos esto es lo que pensaba Rodolfo Llopis cuando años más tarde, en su deseo de justificar los días de «furor laico» de la Segunda República, escribía:

«Llegó la Dictadura. Durante sus años se acusó mucho más el carácter confesional de la enseñanza. Se apoderaron de lo que todavía no tenían. Las teresianas, los manjonianos, los Siurot y cuantos formaban ese sector reaccionario se adueñaron del presupuesto de Instrucción Pública». ${ }^{3}$

La posición eclesial respecto a la Educación en los Estados liberales, que se ha ido fraguando desde el siglo XIX, se recoge en el primer documento oficial dedicado exclusivamente a este tema y que aparece al final del período que nos ocupa, la encíclica Divini Illius Magistri, publicada el 31 de diciembre de 1929. El Estado, a quien le corresponde promover la educación, debe respetar el derecho a educar de la familia y de la Iglesia. ${ }^{4}$ Para los católicos es obligado asistir a una escuela católica, siempre que sea posible, ya que la educación católica no consiste sólo en la asignatura de religión, sino que abarca todas las dimensiones y

\footnotetext{
${ }^{1}$ Afirmación sostenida por gran parte de los historiadores como Paine, S. G. 2006. El catolicismo español: 196. Barcelona: Planeta; Callahan, W. J. 2002. La Iglesia católica en España (1875-2002): 128-129. Barcelona: Crítica; Gallego, A. y Pazos, J. A. 1999. La Iglesia en la España contemporánea. 1800-1936. Madrid: Encuentro; Martí Gilabert, F. 1993. «La Iglesia y la Dictadura de Primo de Rivera». Anuario de Historia de la Iglesia, 2: 151-178.

${ }^{2}$ Cano, L. 2009. Reinaré en España. La mentalidad católica a la llegada de la Segunda República: 137-144. Madrid: Encuentro.

${ }^{3}$ Llopis, R. 2005. La revolución en la escuela: Dos años en la Dirección General de Primera Enseñanza. Edición y estudio introductorio de Antonio Molero Pintado. 232. Madrid: Biblioteca Nueva. Conviene precisar que la subvención que la Fundación Institución Teresiana recibía por su carácter Benéfico-docente fue concedida en la R.O. de 16 de noviembre de 1918, durante el gobierno de Romanones. También de años anteriores son las subvenciones otorgadas a otras instituciones que, clasificadas también como benéfico-docentes, impartían enseñanza gratuita, según lo previsto por el R.D. de 27 de septiembre de 1912. Esto, que comportaba algunas ventajas fiscales, daba la posibilidad de recibir subvenciones estatales y, de acuerdo con la Ley Moyano de 1857, dotaba a los centros educativos así considerados de cierto carácter de «escuela pública». Es el caso, entre otros muchos, de las Academias Teresianas, Escuelas del Ave María y las de Huelva de Siurot.

${ }^{4}$ Divini Illius Magristri, ${ }^{\circ}$ 24. Puede consultarse la edición española en http://www.vatican.va
} 
«Para ello es necesario que toda la enseñanza y toda la organización de la escuela -maestros, programas y libros, en cada disciplina- estén imbuidos del espíritu cristiano, bajo la dirección y vigilancia maternal de la Iglesia, de suerte que la religión sea verdaderamente fundamento y corona de toda instrucción, en todos los grados, no solo en el elemental, sino también en el medio y superior». ${ }^{5}$

Los católicos españoles en estos años estaban convencidos de que un ideario así solo sería posible en un Estado confesional ${ }^{6}$ y con una vuelta al tradicionalismo cultural de acuerdo con los ideales regeneracionistas leídos por los católicos. La Institución Teresiana planteó su actuación teniendo en cuenta el dinamismo social y cultural, adecuando su praxis educativa a un contexto cambiante. Esto la sitúa en los umbrales de la modernidad, ${ }^{7}$ como veremos en las páginas que siguen.

A comienzos de 1924 la Institución Teresiana tiene ya con una cierta entidad por el número de actividades y personas con las que cuenta. Entre la documentación enviada a la Santa Sede en octubre de 1923 para obtener la aprobación pontificia, se describe esta realidad y su crecimiento en poco más de una década:

«Ahora (...) cuenta con 12 Casas, ${ }^{8}$ con 146 Teresianas, ${ }^{9} 150$ Cooperadoras Técnicas, 462 Antiguas Alumnas, 703 Jóvenes Estudiantes, futuras maestras; ahora que la experiencia demuestra la necesidad de la Obra y los beneficios que reporta su acertada organización». ${ }^{10}$

Cifras que se juzgarían irrisorias, comparadas con otras organizaciones si no tuviéramos en cuenta que la mujer apenas había irrumpido en los ámbitos académicos superiores; que en esas fechas los seglares eran considerados la larga mano de la clerecía y con poca libertad de actuación; y que, dada la atmósfera anticlerical que dominaba en amplios sectores de población, la tarea encomendada era particularmente dificultosa.

\footnotetext{
${ }^{5}$ Ibídem, $\mathrm{n}^{\circ} 49$.

${ }^{6}$ Tenemos que contemplar así mismo la posición de la propia jerarquía romana y de algunas otras encíclicas de Pío XI como Quas Primas, publicada el 11 de diciembre de 1925.

${ }^{7}$ Sobre las órdenes religiosas en educación puede consultarse, entre otras publicaciones, Fullana, P. y Ostolaza, M. 2007. «Escuela católica y modernización. Las nuevas congregaciones religiosas en España (1900-1930)», en de la Cueva, J. y Montero, F. (eds.), La secularización conflictiva. España (1898-1931): 187-213. Madrid: Biblioteca Nueva.

${ }^{8}$ Las Casas son los centros en los que desarrolla la Institución Teresiana su actividad más directa a través de los Internados-Academias, escuelas primarias y residencias, entre otras.

${ }^{9}$ Las Teresianas es la denominación habitual para referirse al grupo de mujeres que llevan adelante la actividad, crecimiento e impulso de esta organización con una especial responsabilidad. En otros lugares, refiriéndose a este mismo grupo, nos encontramos con expresiones como «núcleo propulsor» 0 «asociación primaria».

${ }^{10}$ Exposición al Papa Pío XI solicitando aprobación pontificia para la Institución Teresiana, firmada por Josefa Segovia Morón, Madrid, 3 de octubre 1923. Archivo Histórico de la Institución Teresiana (AHIT).
}

Hispania Sacra, LXIV

129, enero-junio 2012, 345-377, ISSN: 0018-215-X, doi: 10.3989/hs.2012.012 
Al finalizar la etapa e incluso en los primeros años de la Segunda República, el crecimiento de la Institución Teresiana es notorio. En la Memoria de 1934 encontramos los datos que reflejan este crecimiento respecto a 1923: las casas son ya 26, el número de alumnas matriculadas asciende a 4.500, las Antiguas Alumnas adscritas son 2.500, las Cooperadoras Técnicas suman 980 y el número de Teresianas casi se ha multiplicado por cuatro llegando a 520. ${ }^{11}$ La Institución, según afirma Poveda en esa misma Memoria, es «oportuna y de actualidad», de ahí los éxitos cosechados a pesar del cambio de circunstancias políticas acaecido con la llegada de la Segunda República.

Para conocer esta oportunidad debemos remontarnos a principios de siglo y buscar los precedentes de la obra povedana.

A la altura de 1911, cuando en España se abrían nuevos horizontes a la mujer en la enseñanza, Pedro Poveda proyectó una Institución para orientar en sentido católico el movimiento cultural femenino, a través del compromiso de seglares católicas que accedieran a la enseñanza oficial. El instrumento del que se valió fueron «Las Academias Teresianas», donde las futuras maestras, estudiantes de las Escuelas Normales, que por esos años terminaban de establecerse en casi todas las capitales de provincia españolas, recibieran una formación integral y complementaria de la que adquirían en los centros oficiales. ${ }^{12}$ Las Academias incorporaban además algunas de las ideas pedagógicas innovadoras del momento siguiendo a autores como Pestalozzi, Herbart, Fröebel, Montessori y el P. Manjón. ${ }^{13}$

Su finalidad última, como todos los esfuerzos del catolicismo social, era recristianizar la sociedad. ${ }^{14}$ Poveda ve urgente que los seglares católicos coordinen sus fuerzas como deseaban la Santa Sede y la jerarquía española. Así lo reflejan las respuestas positivas de algunos obispos a los proyectos de Poveda, entre ellos los cardenales Gregorio María Aguirre, arzobispo de Toledo y Pri-

\footnotetext{
${ }^{11}$ Memoria de la Institución Teresiana 1931-1934. Comenzó a redactarse el 27 de febrero de 1934 y fue entregada en Roma el 17 de abril, elaborada en gran parte por Pedro Poveda. González, E. «Vida y actividades de la Institución entre 1931 y 1936» en Etapa $2^{a}$ : La Institución Teresiana en vida del fundador 1924-1936: 15-25. Materiales de trabajo de la Cátedra Pedro Poveda de Historia de la Institución Teresiana, (Documento inédito).

${ }^{12}$ Véanse Velázquez, F. P. 1996. Las Academias, Madrid: Narcea; Flecha García, C. 1988. «La primera Residencia universitaria femenina en España», en A.A. V.V., Pedro Poveda, Volumen-Homenaje cincuentenario 1936-1986: 321-335. Madrid: Narcea, y García Hoz, V. 1974. La pedagogía de Pedro Poveda y la formación de educadores. Discurso pronunciado por... en la Sesión conmemorativa en la UNESCO con ocasión del nacimiento de Pedro Poveda. París: UNESCO.

${ }^{13}$ Véanse los folletos publicados La Institución Teresiana. Academia de Linares, Imprenta San José, Linares, 1916 y La Institución Teresiana. Internado de Jaén, Talleres de La Regeneración, Jaén, 1916, con textos muy similares, dirigidos a dar a conocer ambas Academias.

${ }^{14}$ Véase Revuelta González, M. 2005. La Iglesia española en el siglo XIX. Desafíos y respuestas. Madrid: Universidad Pontificia Comillas. Asimismo de la Cueva, J. y Montero, F. 2007. (eds.), La secularización conflictiva ...
} 
mado, Enrique Almaraz Santos, arzobispo de Sevilla y del que más tarde (1914) sería prelado valenciano y posteriormente Primado de España, Enrique Reig Casanova. ${ }^{15}$

La posición de Poveda no es una respuesta reactiva ante las dificultades del momento, sino alternativa. ${ }^{16}$ Es consciente del protagonismo del Estado y su creciente esfera de acción en la educación, pero no comparte del todo la posición de Manjón, que desarrolla una importante campaña editorial contra lo que él llama «el intrusismo del Estado», ni de Razón y Fe, la revista de los jesuitas, que se opone radicalmente a la estatalización creciente de la enseñanza. El camino de Poveda es «dispar» pues acepta esta mayor intervención del Estado como realidad irreversible, que no estaba en su mano modificar, ${ }^{17} \mathrm{y}$ alienta a los seglares a la acción en las estructuras estatales, animándoles a que ingresen en todos los estamentos de la enseñanza oficial para que la presencia del cristiano tenga una redoblada eficacia. ${ }^{18}$ Así lo había propuesto también el cardenal Aguirre en sus Normas de Acción Católica y Social de 1910, cuando subraya en el punto 4:

«...es útil sobremanera que los buenos católicos y los eclesiásticos que se hallen en condiciones, luchen para ingresar en el Profesorado oficial y, especialmente, en las Escuelas Normales del Magisterio». ${ }^{19}$

La Institución Teresiana tuvo sus precedentes en el diseño de una Institución Católica de Enseñanza que Poveda pensó en 1911 como un instrumento de unión y actualización profesional de todos los católicos y todas las obras católicas dedicadas a la Enseñanza. Su primer fin sería:

${ }^{15}$ Pedro Poveda envió su escrito, Ensayo de un proyecto pedagógico para la fundación de una «Institución Católica de Enseñanza», a la jerarquía eclesiástica y a todos los religiosos y seglares católicos cuya labor se destacaba en el campo educativo. A partir de septiembre de 1912 -cuando ya tenía buen número de respuestas, copió de su puño y letra las que le resultaban más interesantes en un registro privado que titula «Historia de los Folletos» agrupando las respuestas. Véase el estudio preliminar de Galino, A. 1964. «Estudio preliminar» en Poveda, P. Itinerario Pedagógico: 47-56. Madrid: C.S.I.C. y Velázquez, F. P. 1987. Proyectos pedagógicos. Madrid: Narcea. El texto del escrito se puede consultar en Poveda, P. 1989. Folletos. Edición facsimil, Madrid: Publicaciones del Archivo de la Institución Teresiana, y Poveda, P. 1964. Itinerario Pedagógico..., 107-127.

${ }^{16}$ Véase Pego Puigbó, A. 2006. Modernidad y pedagogía en Pedro Poveda. La experiencia de Covadonga: 33-120. Salamanca: Universidad Pontificia de Salamanca, Cátedra «Pedro Poveda».

${ }^{17}$ El profesor Sanz de Diego ha matizado así los diferentes puntos de vista: para Ruiz Amado, la enseñanza no es función política, sino social, porque enseñar no es atributo de la soberanía ni el magisterio es cargo público ni el Estado puede dar verdadera garantía a la enseñanza, y «Poveda aceptó la estatalización creciente de la enseñanza como un dato irreversible que no estaba en su mano modificar». Sanz de Diego, R. M. 1988. «Pedro Poveda, lector de «Razón y fe» en Covadonga», en A.A. V.V., Pedro Poveda, Volumen-Homenaje cincuentenario 1936-1986: 155. Madrid: Narcea.

${ }^{18}$ Véase Poveda, P. Itinerario..., 40.

${ }^{19}$ Reig Casanova, E. 1926. Principios y bases de la reorganización de la Acción Católica Española, promulgadas por su director pontificio, el Emmo. y Rvdmo. Sr. D. Enrique Reig y Casanova: 123-132. Toledo: Imprenta de la Editorial Católica Toledana.

Hispania Sacra, LXIV

129, enero-junio 2012, 345-377, ISSN: 0018-215-X, doi: 10.3989/hs.2012.012 
«Formar, según el espíritu cristiano y ajustándose a los mejores métodos pedagógicos, un cuerpo de profesores de primera enseñanza, a quienes presentará anualmente a oposiciones a fin de obtener el mayor número de plazas en las oposiciones a escuelas públicas.» ${ }^{20}$

Hacia 1914 Poveda estaba convencido de que la Institución Católica de Enseñanza no cuajaba, tal y cómo la había concebido, a pesar de las buenas palabras de obispos, superiores de órdenes religiosas, maestros etc. No obstante él había iniciado la fundación de las Academias-Internados. Algunas tenían escuelas primarias donde los futuros maestros pudieran realizar sus prácticas y un Centro Pedagógico para los maestros en ejercicio, ${ }^{21}$ como se recogía en el proyecto de inicial. Con estas actividades comienza la Institución Teresiana. ${ }^{22}$

A partir de 1923 comienza una nueva actividad que se une a las ya existentes en las Academias: facilitar los estudios de bachillerato a las mujeres.

Con este fin se creó el «Instituto Católico Femenino» en 1924. ${ }^{23}$ Un centro de bachillerato que preparaba, mediante estos estudios, el acceso de la mujer a la universidad. En noviembre de 1923 se hizo la presentación del Instituto con las razones de su creación y el programa de sus enseñanzas:

«El Instituto Católico Femenino, convencido de que la mujer, por mucho que se engolfe en los problemas de la investigación científica, no puede ni debe olvidar su fe y feminidad, y teniendo en cuenta la educación integral que necesitan las jóvenes que estudian bachillerato, las formará en su clase de Religión sólidamente piadosas, y establecerá, al lado de sus laboratorios y museos, una clase de Labores útiles y Economía doméstica, y compartiendo el tiempo con sus estudios literarios y conferencias y excursiones científicas, atenderá a la enseñanza de la música, del canto y de la recitación, y en su campo de juego dará suma importancia a la educación física; en una palabra, distribuirá el tiempo de que disponen las alumnas -siempre suficiente cuando se aprovecha bien- de tal manera que éstas se formen sanas de cuerpo y de espíritu, inteligentes y activas, y en su

\footnotetext{
${ }^{20}$ Poveda, P. 1989. Folletos, Edición Facsímil. Madrid: Publicaciones del Archivo de la Institución Teresiana.

${ }^{21}$ No sabemos de otros Centros Pedagógicos que los creados en Gijón, en diciembre de 1911 y en Linares en 1913.

${ }^{22}$ Las Academias se van implantando en distintas ciudades españolas. Las existentes en 1923 siguiendo el orden cronológico de creación son: Oviedo (1911), Linares (1912), Jaén (1913), Madrid (1914), Málaga (1914), León (1917), Barcelona (1918), Teruel (1918), Burgos (1919), Ávila (1919), San Sebastián (1920), Córdoba (1921). Otros muchos lugares fueron objeto del interés de Poveda pero no tuvieron éxito sus gestiones. Pueden conocerse los pasos efectuados para estas fundaciones en el Libro de las Fundaciones, cuaderno manuscrito iniciado por Poveda en 1915 hasta 1919 y en las Fichas elaboradas por Josefa Segovia en 1955. Véase Poveda, P. 1968. Escritos Espirituales. Madrid: Iter Ediciones, 725-759 y Josefa Segovia, Fichas de historia de la Obra, 1955, AHIT. Asimismo el Boletín de la Institución Teresiana (BIT) dará cuenta de las distintas Academias, desde su creación en 1913 en Linares.

${ }^{23}$ Aunque el proyecto se venía pensando desde 1919, hasta 1924 no se decidió el local adecuado para la instalación, que concluye siendo el de la misma Academia, en la calle Alameda. En 1926 se trasladó a Alcalá, 105, un edificio más idóneo para las objetivos que se perseguían.
} 
mente lleguen a fulgurar los destellos de la ciencia y en su corazón arraigue el atractivo irresistible de la virtud». ${ }^{24}$

Hay que recordar la negativa de los católicos a la coeducación, de ahí que el programa esperase «una favorable acogida (...) principalmente de los padres católicos». ${ }^{25}$ Posibilitaba la realización del bachillerato en un centro femenino y con profesorado femenino: no era necesario elegir entre la asistencia a los institutos oficiales, mixtos, o renunciar a estos estudios.

Este centro privado de bachillerato elemental y universitario estaba incorporado al Instituto de San Isidro en Madrid, siendo uno de los pocos centros femeninos de esas características y el primero que se incorporaba a este Instituto. ${ }^{26}$ Estos estudios abrían las puertas a la Universidad, algo que desde la carrera de magisterio resultaba imposible. La primera directora del «Instituto Católico Femenino» fue Carmen Cuesta del Muro. ${ }^{27}$

Por otra parte, tiene especial relevancia el interés de estas iniciativas desde el campo católico, teniendo en cuenta el gran reto que suponía para la mujer el acceso a la enseñanza superior. ${ }^{28}$

En esta misma línea cabe señalar la importancia de la iniciativa teresiana con relación a las residencias universitarias, por el impulso que también suponía en el acceso de la mujer a los estudios superiores. A esto había respondido anteriormente la creación de la Residencia Femenina Universitaria de Madrid en 1914 y el impulso de otras en años posteriores en distintas ciudades.

En mayo de 1924 se celebró en Madrid el I Congreso Nacional de Educación Católica. Este acontecimiento estaba previsto en la agenda de los Metro-

${ }^{24}$ BIT, noviembre $1923, n^{\circ} 108$, p. 25.

${ }^{25}$ En el Congreso Nacional de Estudiantes Católicos de Zaragoza, realizado del 24 al 28 de enero de 1923, un grupo de mujeres de la Institución Teresiana, plantean la creación de Institutos Católicos Femeninos. Véase Velázquez, F. P. 2003. Pedro Poveda en Madrid: 86-87. Madrid: Narcea.

${ }^{26}$ Araque Hontangas, N. 2010. La educación secundaria femenina 1900-1930. Madrid: Universidad Complutense, 131-133.

${ }^{27}$ Carmen Cuesta del Muro (1890-1968). Procedente de la Escuela Superior de Magisterio fue profesora de la Escuela Normal de Teruel y a partir de 1922 profesora de Sociología de la Escuela del Hogar y Profesional de la Mujer. Se licenció en Derecho en 1924 y fue la primera mujer que obtuvo el doctorado en esta materia en España unos años después. Ocupando los cargos de Secretaria y Presidenta de la Asociación de Cooperadoras Técnicas de la Institución Teresiana en los primeros años de misma, colaboró de manera muy especial en su consolidación, desarrollo y actividad. Desempeñó importantes cargos en la vida pública española. A partir de 1933 desarrolló su actividad en América hasta su jubilación.

${ }^{28}$ En el distrito universitario de Madrid durante el curso 1914-1915 frente a un total de 2.393 varones inscritos, el de mujeres matriculadas era de 70. Sobre la promoción educativa de la mujer, entre otros: Capel, R. M. 1986. El trabajo y la educación de la mujer en España 1910-1930. Madrid: Instituto de la Mujer. Otras autoras aportan datos interesantes sobre el tema como: Flecha García, C. 1999. Las primeras universitarias españolas. Madrid: Narcea y Montero, M. 2009. La conquista del espacio público: mujeres españolas en la Universidad (1910-1936). Madrid: Minerva.

Hispania Sacra, LXIV

129, enero-junio 2012, 345-377, ISSN: 0018-215-X, doi: 10.3989/hs.2012.012 
politanos como una «demostración de la pujanza intelectual de la escolaridad católica». ${ }^{29}$

El 5 de febrero de 1923 el obispo de Valladolid, Remigio Gandásegui Gorrochátegui, envía una tarjeta a Pedro Poveda. Lo invita a una reunión general de prelados para organizar el Congreso de cuyo Comité Ejecutivo formaría parte. ${ }^{30}$ Poveda ve con buenos ojos esta oportunidad que permite dar a conocer la labor de la Iglesia y de la Institución Teresiana. ${ }^{31}$ Aunque las fechas eran particularmente desafortunadas, ${ }^{32}$ inmediatamente puso en «la agenda» nombres de personas de la Institución y posibles temas para participar en el Congreso. Se puede decir que figuraban profesionales de gran competencia, muchas tituladas de la Escuela de Estudios Superiores de Magisterio.

Asistieron al Congreso en nombre de la Institución 161 personas, 28 procedían de sus distintas asociaciones, y presentaron 45 Memorias. Fueron ponentes 11 y 22 formaban parte de la Junta organizadora general y de las distintas secciones. En la de Conferencias de la Biblioteca Nacional hubo varias dedicadas al origen, fines y medios de la Institución Teresiana y al funcionamiento de sus Asociaciones. ${ }^{33}$ En la exposición pedagógica estuvo presente con doce cuadros con fotografías de sus centros, álbumes fotográficos y una Memoria, resumen de la labor de la Institución desde sus comienzos. ${ }^{34}$

Los asuntos educativos expuestos por quienes intervinieron incluían buen número de Secciones, destacando especialmente la $8^{\mathrm{a}}$, dedicada a «Obras cir-

${ }^{29}$ Casas, S. 2006. «La Agenda de la Conferencia de Metropolitanos», en Jaime Aurell i Cardona y Pablo Pérez López (eds.). Católicos entre dos guerras. Madrid: Biblioteca nueva, 231-254. Sobre este acontecimiento, ver también Adagio, C. 2004. Chièsa e Nazione in Spagna. La ditatura de Primo de Rivera (1923-1930). Milano: Unicopli, 100-111.

${ }^{30}$ El Comité estaba formado por el P. Ruíz Amado, Segundo Espeso, Rufino Blanco, Miguel Vegas y Pedro Poveda. En Pedro Poveda, Diario, (5 de febrero 1923) AHIT.

${ }^{31}$ Poveda había manifestado su deseo de que la Institución se diera a conocer y participara en cuantos eventos organizara la Iglesia.

${ }^{32}$ Durante el segundo semestre de 1923, la Institución Teresiana dedicó muchos de sus esfuerzos a preparar la solicitud de la aprobación pontificia: documentación, viaje y gestiones. El primer trimestre de 1924 todas las personas convocadas para contribuir al Congreso tuvieron una actividad desbordante como revela Josefa Segovia «(...) termina el mes [de marzo] con el mayor agobio que yo recuerdo. Congreso con temas, exposición, alojamientos. Enfermedades, falta de dinero; asuntos de las casas sin poderlos resolver ni atender» (Diario de la I.T. 31 de marzo de 1924).

${ }^{33}$ Según los datos reseñados en la publicación de las Actas y cotejados con la documentación del Archivo Histórico de la Institución Teresiana. Primer Congreso Nacional de Educación Católica. Madrid, 21-26 de abril de 1924. Madrid: Tipografía de la «Revista de Archivos», 1925.

${ }^{34}$ Así aparece su presencia en algunas publicaciones de la época: «Pero vamos ya a las salas de arriba. Fíjate ya aquí, de paso, en esta modesta Institución Teresiana, y si eres de los pesimistas que creen que España va en todo a la zaga, sabe que Cardenales de la iglesia se interesan por esta salvadora obra y quieren copiarla en Italia». Restrepo, F. 1924 «El Congreso de Educación y la Exposición pedagógica». Razón y Fe, 69: 149. También «El Primer Congreso de Educación Católica y la Institución Teresiana» BIT, 115 (1924) 144. 
cum y postescolares», cuya presidenta era Josefa Segovia. ${ }^{35}$ En ella trabajaron con empeño Eulalia García Escriche, Magdalena M. Ayuso, Ana María Sanz, M ${ }^{a}$ Antonieta Freixá, Teresa de Jesús Álvarez, Carmen de la Vega, Mariana Ruíz, Rafaela García de la Cruz, Francisca Molina, Victoria Grau, Maria de Echarri, Carmen Cuesta, Maria Puigserver, Josefa Bris y Catalina García Trejo. ${ }^{36}$ Todas fueron protagonistas en este periodo histórico de la Institución.

Entre las conclusiones del Congreso, las que hacían referencia a los aspectos relacionados con la enseñanza oficial, enseñanza de la mujer, participación de los padres, y Escuelas Normales y residencias interesaron de modo especial a la Institución Teresiana:

- Creación de Institutos de segunda enseñanza para la mujer

- Que los futuros maestros adquieran conocimientos de la ciencias fundamentales de la Pedagogía

- Que las Escuelas Normales de maestras conserven su organización independiente de las de los maestros

- Fomento de bibliotecas escolares y pedagógicas.

- Fomento de colonias, mutualidades, cantinas y roperos escolares

- Derecho del niño a la educación religiosa

- Residencias católicas de estudiantes

- Urgencia de crear obras postescolares para salvar los frutos de la educación recibida en la escuela.

- Creación de asociaciones de padres y madres de familia en torno a las obras educativas

- Que en los centros docentes deben implantarse las Asociaciones femeninas de estudiantes católicas para llegar a que la Confederación agrupe a todas las escolares de España. ${ }^{37}$

Fueron estas, sin excluir otras, las que marcaron líneas seguidas luego con más empeño. En gran parte quedaron reflejadas en las páginas del Boletín de Institución Teresiana.

Es evidente que la participación en este Congreso contribuyó al conocimiento de la Institución y le dio prestigio en ámbitos católicos. ${ }^{38}$

\footnotetext{
${ }^{35}$ El Primer Congreso Nacional..., 13.

${ }^{36}$ La mayoría son profesoras de Escuela Normal y su participación responde a una propuesta personal de Pedro Poveda, según consta en las hojas manuscritas que se conservan en AHIT.

${ }^{37}$ Primer Congreso Nacional..., 200-210.

${ }^{38}$ Cuando D. Pedro Segura, obispo de Coria en ese momento y miembro de la mesa que preside la sección $8^{\mathrm{a}}$, entra en contacto con Pedro Poveda y le pide que se haga una fundación en Cáceres, éste anota en sus Diario, «Todo salió del Congreso». Pedro Poveda, Diario, 13 de junio de 1924. 


\section{Relación con la naciente Acción Católica de la Mujer}

Es conocida la colaboración de la Institución Teresiana en el nacimiento de la Acción Católica de la Mujer (ACM) ${ }^{39}$ en su posterior desarrollo y en su discurso feminista:

«De gran importancia resultó (...) el Instituto Teresiano para la formación de cuadros medios y activistas de primer nivel del movimiento católico femenino español, así como la creación del discurso feminista católico de Acción Católica de la Mujer (...). Carmen Cuesta resultó ser su militante y propagandista más destacada e incansable.» ${ }^{40}$

Rebeca Arce cita especialmente a María de Echarri, ${ }^{41}$ Carmen Cuesta, ${ }^{42}$ y Josefa Segovia. Destacaron notoriamente, además, Josefina Olóriz, Carmen Fernández Ortega, María Bris, Ana María Sanz y Antonieta Freixá. Otras, sin pertenecer a la Institución Teresiana, mantenían relación estrecha con ella, como: Cristina de Arteaga, presidenta de las Estudiantes Católicas y asidua a la Academia de Madrid, María López Sagredo y Francisca Bohigas, entre otras.

Según los datos que conocemos, María de Echarri fue la más vinculada a la Acción Católica de la Mujer. Conocida publicista y secretaria del Sindicato

${ }^{39}$ Véanse Blasco, I. 2003. Paradojas de la ortodoxia. Política de masas y militancia católica femenina en España (1919-1939). Zaragoza: Prensas Universitarias de Zaragoza; Moreno Seco, M. 2005. «Mujeres, clericalismo y asociacionismo católico», en A.A. V.V., Clericalismo y asociacionismo católico en España: de la restauración a la transición: 107-133. Cuenca: Centro de Estudios Castilla-La Mancha; García Checa, A. 2007. Ideología y práctica de la acción social católica femenina (Cataluña, 1900-1930). Málaga: Universidad de Málaga y Arce Pinedo, R. 2008. Dios, Patria, Hogar. La construcción social de la mujer española por el catolicismo y las derechas en el primer tercio del siglo XX. Santander: Universidad de Cantabria.

${ }^{40}$ Arce Pinedo, R. 2008: 102 recoge esta afirmación de un artículo publicado en El Universo. Revista de Acción Católica y Cultura General, 52 (29-IV-1927).

${ }^{41}$ Maria de Echarri (1878-1956) se vinculó a la Institución Teresiana hacia 1925. Tuvo diferentes contactos epistolares con Poveda desde la temprana fecha de 1910 cuando este era canónigo de Covadonga, a raíz de un artículo suyo publicado en El Carbayón, pero posiblemente no se conocerían personalmente hasta el año 1917, Diario de la I.T. (29 de enero de 1917). Véase también Rosique, F. 1988. «Diálogos de Poveda con la mujer, la figura de María de Echarri», en A.A. V.V., Pedro Poveda, Volumen-Homenaje..., 336 y ss. Josefa Segovia (1891-1957) conoció a Pedro Poveda en Jaén en 1913. Había estudiado en la Escuela Superior del Magisterio, y Poveda le ofreció la dirección de la Academia de Jaén. A partir de 1918 será Directora de la Institución Teresiana, cargo que desempeñó hasta su muerte en 1957. Durante siete años compaginó sus responsabilidades en la Institución con el puesto de inspectora de Enseñanza Primaria en la provincia de Jaén. En el período que fue Directora de la Institución Teresiana ésta se extendió por numerosos países de América latina, Asia, África y Europa. Sobre Josefa Segovia, entre otros estudios, ver González, E. 2006. Pasión por la santidad. Biografía de Ma Josefa Segovia, Madrid: B.A.C. y A.A. V.V. 1993. Josefa Segovia. Volumen-homenaje. Primer Centenario de su nacimiento 1891-1957. Madrid: Narcea. Sobre algunos datos biográficos de Carmen Cuesta ver nota 21.

${ }^{42}$ De Carmen Cuesta dice, erróneamente, que es la Presidenta de la Institución Teresiana. Es posible que exista una confusión con la denominación del «Instituto Católico Femenino», el centro de bachillerato del cual fue directora. 
Femenino Católico de la Inmaculada, más tarde, en 1918, inspectora de Trabajo de Madrid y Concejal del Ayuntamiento madrileño en 1924.

Cuando en 1919 el cardenal Victoriano Guisasola Menéndez crea la rama femenina de Acción Católica, ${ }^{43}$ ésta se estableció en el domicilio de la Academia Teresiana de la calle Serrano. ${ }^{44}$ María de Echarri formaba parte de su primera Junta, presidida por la Marquesa de Gavia y se encargó de las relaciones con el extranjero, pues hablaba inglés y francés y se movía con soltura en viajes y encuentros fuera de España.

«He asistido a muchísimos Congresos Católico-Sociales en Roma, varios en Holanda, Luxemburgo, Suiza, en representación de España, de la ACM primero, de la Acción Católica de la Mujer de España después, en los Congresos Internacionales de Ligas Femeninas como secretaria nacional en los Congresos Católicos Internacionales de Obras de protección de las Jóvenes... En París, representando a España en Congresos para estudiar y resolver el problema de la «vuelta al hogar de la madre obrera». ${ }^{45}$

Era también una oradora habitual en las Semanas de Acción Católica como la de Barcelona ${ }^{46}$ Andújar, etc. y en otros muchos actos y congresos.

En el Homenaje, que con ocasión de sus 25 años de publicista le tributó el Boletín Institución Teresiana, se la califica como «leader femenino de las libertades cristianas» y reenumeran sus méritos: escribió innumerables artículos, pronunció discursos, fue vocal del Instituto de Reformas Sociales y de la Junta de Emigración. Incansable su labor en la Acción católica y en los Sindicatos Católicos Femeninos. ${ }^{47}$

María, escritora habitual en el Boletín, en sus páginas anima a la colaboración con esta asociación de Iglesia. Habla de la Acción Católica como

«(...) obra de seglares. Es la cooperación de éstos a la empresa apostólica. (...) Quisiéramos saber qué contestarán las señoras y señoritas, que suelen negarse a cooperar a esta obra de Cristo y de su Iglesia, cuando se solicita de ellas su actuación...Escusa [sic.] no tienen ninguna». ${ }^{48}$

\footnotetext{
${ }^{43}$ En opinión de Gómez Molleda la creación de la ACM en 1919, obedecía en gran parte al objetivo de neutralizar la influencia de otros movimientos de otro signo. Véase Gómez Molleda, M. D. 2005. Pedro Poveda, Obras I. Creí por esto hablé. Edición crítica y estudio. Madrid: Narcea, 794.

${ }^{44}$ También la ACM tuvo su domicilio social en los Internados de Cordoba (BIT, $\mathrm{n}^{\circ}$ 101, abril 1923) y San Sebastián (Hoja impresa Institución Teresiana. Memoria (curso 1924 a 1925), Oviedo, Huesca, Bilbao, Zaragoza, Recogido por Carmen Cuesta, en el Diario del centro de Serrano 16, Madrid, 1 de noviembre 1918 a 1920, tomado de Gómez Molleda, M. D. 2005: LXXII.

${ }^{45}$ Relación autobiográfica de María de Echarri, AHIT.

${ }^{46} B I T, \mathrm{n}^{\circ} 102$, abril 1923, 110 .

${ }^{47} B I T, \mathrm{n}^{\circ} 125$, abril 1925, 116 .

${ }^{48} B I T, \mathrm{n}^{\circ} 140$, julio 1926,184 .
}

Hispania Sacra, LXIV

129, enero-junio 2012, 345-377, ISSN: 0018-215-X, doi: 10.3989/hs.2012.012 
Su pensamiento recogido en la sección «Movimiento católico feminista», en la «Revista Católica de Cuestiones Sociales», se podría sintetizar: rehabilitación de la feminidad, defensa del protagonismo de las Mujeres: «un nosotras que desde el feminismo católico lucha contra el Mal», la conveniencia de las mujeres de extracción elevada para la dirección de la lucha feminista católica y sus obras sociales como armas del feminismo católico. ${ }^{49}$

Carmen Cuesta del Muro, doce años más joven que María de Echarri, se vinculó tempranamente al catolicismo social ${ }^{50}$ y a la Acción Católica. Ella, con Segovia, Echarri, Luzzati, Maqua, Raposo y María López Sagredo, eran «la auténtica élite intelectual del feminismo católico español de la década de los $20 \gg .{ }^{51}$

Entre sus muchas intervenciones, citamos su ponencia, «La Maestra, apóstol de los intereses morales, jurídicos y económicos de la Mujer», en el Ciclo de estudios católico-sociales, organizado por la Junta de Acción Católica de la Mujer de Vizcaya. Destaca la coherencia y la solidez de ideas. Urgió a las jóvenes a elegir la carrera de Magisterio, pues es necesario ser apóstoles en la «restauración del orden social», y la espiritualización de la vida que reclama una preparación especial «que dé al Magisterio unidad de criterio, y unidad de ideal, y unidad de fin y de sentimientos (...). A esto se llega con un estudio serio de la Religión y de las Ciencias Sociales». ${ }^{52}$

En 1926 el Gobierno de Primo de Rivera subvencionó a la Acción Católica de la Mujer para hacer propaganda de acercamiento en los países de Hispanoamérica. Para esta labor la Acción Católica contó con la colaboración de la Institución Teresiana que envió a Carmen Cuesta. Rufino Truébano, consiliario de la Acción católica de Asturias y miembro también de la expedición, entrevistado por «El Debate» en octubre, habló de las intervenciones de Cuesta: «La competencia de Carmen Cuesta evidencióse en las diversas conferencias y salutaciones a que se vio obligada; pero brilla de modo singular en el magnífico discurso pronunciado -a petición de las señoras uruguayas- en la Universidad

\footnotetext{
${ }^{49}$ «...tras el término 'mujer social' subyacía la pretensión de aprovechar su energía para luchar contra modernas tendencias que atacaban la religión, y para frenar lo que se percibía como un proceso de secularización irreversible y de alejamiento de las masas de la Iglesia y del catolicismo». Véase Blasco, I. 2003. Paradojas de la ortodoxia. Política de masas y militancia católica femenina en España (19191939). Zaragoza: Prensas Universitarias de Zaragoza, 68.

${ }^{50}$ Ya, en 1915, el mismo año que terminó sus estudios en la Escuela Superior del Magisterio, pronunció un curso de conferencias organizados por los Centros Obreros Catequistas de Madrid. Cuesta del Muro, C. 1915. La vida y el obrero. Curso de conferencias dadas a los obreros de Madrid. Madrid: Tipografía del Sagrado Corazón.

${ }^{51}$ Arce Pinedo, R. 2008: 109. Si bien esta autora se centra en Echarri, Cuesta y Segovia, sabemos que el grupo es más numeroso. Entre ellas, Carmen Raposo, que era Directora de la Escuela Normal de Barcelona y Cooperadora Técnica de la Institución Teresiana y María Sagredo, de la que se conoce su contacto muy estrecho con la Institución. Diario de la Institución Teresiana, (26/11/1927), $(15 / 02 / 1928)$ y $(01 / 02 / 1929)$.

${ }^{52}$ Boletín de Acción Católica y de Cultura General, no 34, 24 de diciembre 1929, citado por Arce Pinedo, R. 2008: 112-113.
} 
de Montevideo, cuya cátedra se abrió por vez primera para una conferenciante católica, ante concurrencia desbordante y con éxito entusiasta». ${ }^{53}$

Josefa Segovia no tuvo el protagonismo de María de Echarri y Carmen Cuesta en esta relación de colaboración con la Acción Católica, dadas sus responsabilidades como Directora General de la Institución. Asumió, sin embargo, las decisiones fundamentales en relación con la Acción Católica y lo que la Iglesia le encomendaba, como la colaboración en el Congreso de Educación Católica, y el proyecto de las Estudiantes Católicas en los epígonos de la etapa primorriverista, alentado por el Cardenal Segura. ${ }^{54}$

A partir de 1927 los obispos, especialmente aquellos en cuyas diócesis había distritos universitarios, y el Director pontificio de la Acción Católica, comenzaron a preocuparse por los estudiantes universitarios. El crecimiento de la enseñanza superior había sido espectacular en los últimos años, pasando de 18.969 alumnos en el curso de 1922-1923, a casi 60.000 en el curso 1929-1930.55

El acceso de la mujer a la universidad, aunque lento, había sido también progresivo, alcanzando en 1927 sus cifras más altas. ${ }^{56}$ Poveda percibió el interés que este fenómeno tenía para la mujer y la necesidad de crear residencias universitarias que no contemplasen únicamente la entrada en la Escuela Normal sino en las distintas Facultades. ${ }^{57}$

La Institución Teresiana inició en 1929 una residencia universitaria en Santiago de Compostela aprovechando que, al clausurarse la Universidad de Madrid a causa de las agitaciones estudiantiles, los estudiantes acudían a examinarse a Santiago. A ésta siguieron otras en distintas ciudades en los años $30 .{ }^{58}$

${ }^{53}$ El Debate 12 de octubre 1926. Citado por Azaustre, C. en «Cuadernos de la Cátedra de Historia de la Institución Teresiana», Cuaderno 3, El grupo de las primeras en la obra de Poveda, 57 (inédito).

${ }^{54}$ Sobre historiografía de la Acción Católica, en general y, durante la etapa del Cardenal Segura, merecen especial mención los estudios de Feliciano Montero y otros nombres como: José Leonardo Ruíz, Enrique Berzal, José Ramón Rodríguez lagos, Francisco M. Hoyos, Joan Matas Emilio Grañido. Montero, F. 1993. El movimiento católico en España. Madrid: Eudema. Asimismo Montero F. (coord.) 2008. La Acción Católica en la Segunda República. Alcalá de Henares: Universidad de Alcalá.

${ }^{55}$ Véase González Calleja, E. 2005. La España de Primo de Rivera. La modernización autoritaria 1923-1930. Madrid: Alianza: 86.

${ }^{56}$ Instituto Nacional de Estadística. 1952. Principales actividades de la vida española en la primera mitad del siglo $X X$, Madrid.

${ }^{57}$ Desde los primeros momentos de la creación de la Academia de Madrid (1914) hubo estudiantes de Farmacia, Medicina, Ciencias y Letras. Véase Hoja impresa Institución Teresiana. Memoria (curso 1924-1925), AHIT.

${ }^{58}$ «Caracterizante de este periodo es la presencia en ambientes universitarios, concretada en mayor número de estudiantes, nuevas residencias y nuevas asociaciones». González, E. «Vida y actividades de la Institución entre 1931 y 1936» en Etapa $2^{a}$ : La Institución Teresiana en vida del Fundador 19241936, Materiales de trabajo de la Cátedra Pedro Poveda de Historia de la Institución Teresiana, doc. 20, (documento inédito): 99-104.

Hispania Sacra, LXIV

129, enero-junio 2012, 345-377, ISSN: 0018-215-X, doi: 10.3989/hs.2012.012 
Ese mismo año, el cardenal Segura, arzobispo de Toledo, encargó a Pedro Poveda que la Institución organizara la Asociación Católica Femenina de Estudiantes,$^{59}$ del mismo modo que funcionaba ya la asociación de varones vinculada a la Asociación Católica Nacional de Propagandistas.

Esta nueva actividad fue tomada en peso y con interés por la dirección de la Institución Teresiana, así se refleja el inicio de esta asociación:

«Tiempo hacía que [Pedro Poveda] pensaba en la necesidad de organizar o reorganizar las asociaciones femeninas católicas de estudiantes, y aprovechando que la federación masculina de Madrid había pedido nuestra colaboración, o mejor dicho, nos había pedido la dicha organización, hechas las consultas necesarias, se procedió a ello abriendo una Casa Social para las Estudiantes Católicas de Madrid en la Carrera de San Jerónimo y encomendando la inmediata dirección a la Srta. Grosso». ${ }^{60}$

El mismo Poveda, en 1930 y a propósito de la mujer universitaria, escribió un texto programático en el que, bajo el título Nuestro Programa, fe y ciencia, subraya su desacuerdo ante el hecho de establecer antagonismo entre la fe y el mundo moderno. Se opone, así mismo, a aquellos que ven en la ciencia un peligro para la piedad de la mujer: «La cultura sólida de nuestras doctoras y licenciadas debe ser el mentís más rotundo de todas esas afirmaciones» ${ }^{61}$

La Asociación de Estudiantes Católicas tendrá su franca expansión a partir de $1933 .{ }^{62}$

\section{LA PROYECCIÓN EDUCATIVA: UNA APROXIMACIÓN A LAS COOPERADORAS TÉCNICAS}

La Asociación de Cooperadoras Técnicas es una Asociación de mujeres católicas profesionales de la educación, liderada por la Institución Teresiana, que desarrolla su actividad fundamentalmente en la década de los '20. Responde a uno de los rasgos configuradores del inicial proyecto de la Institución Católica de Enseñanza que tenía como objetivo unir a los educadores católicos. En esos años representa una aportación original desde el catolicismo a la educación española en el ambiente de regeneracionismo y de debate, iniciado a principios de siglo. La obra de Poveda había abierto un nuevo campo a los educadores católicos: los centros oficiales para, desde ellos, trabajar, asociados, por la mejora de la educación española.

\footnotetext{
${ }^{59}$ La Asociación funcionaría en dos ramas, una de tituladas universitarias y otra de estudiantes. La sede de la nueva asociación se estableció en la Carrera de San Jerónimo y más tarde en la Calle del Carmen, que pronto se convertiría en un activo centro de animación juvenil. Tomado de Gómez Molleda, M. D. 2006: 842-843.

${ }^{60}$ Actas del Directorio, 1918-1928, 27 de febrero 1928. AHIT.

${ }^{61}$ Véase Gómez Molleda, M. D. 2006: 673.

${ }^{62}$ Ibídem: 1062.
} 
El movimiento asociacionista en educación comienza en colectivos del magisterio, y tiene sus orígenes a finales del siglo XIX, cuando agrupaciones de maestros, de carácter local, inician sus actividades pidiendo mejoras en su trabajo y en las condiciones materiales de las escuelas. En los inicios del siglo XX había comenzado el proceso de nacionalización de la enseñanza primaria, con su financiación estatal, mayor independencia del maestro de los ayuntamientos, creación de un cuerpo de inspectores y el establecimiento del escalafón. Con esto la situación de los maestros fue mejorando,$^{63}$ aunque lentamente y, en buena medida, debido a las reivindicaciones corporativas presentadas por las distintas asociaciones.

En 1901 se había constituido la Asociación Nacional del Magisterio con una estructura federal que se inicia en el partido judicial y conecta con provincia y distrito universitario. En los primeros años tuvo un crecimiento rápido gracias a la organización de las numerosas asociaciones provinciales. En 1911 se cifran en unos 15.000 los afiliados. ${ }^{64}$

La Junta directiva nacional debía estar presidida por un diputado o senador a Cortes, domiciliado en Madrid, de reconocido amor a la enseñanza y de notoria influencia política.

A partir de 1911, momento en que se hace público el escalafón general del magisterio, comenzó la separación de distintos grupos: la Asociación General de Maestros, la Unión Nacional de Maestros y la Liga de Maestros Rurales. Son asociaciones más reivindicativas y acusan a la Asociación Nacional del Magisterio de mantener una política conciliatoria, colaboracionista, demasiado «pedagogista», con pocas reivindicaciones salariales que las nuevas consideraban prioritarias.

La Asociación General de Maestros, vinculada a la UGT, tuvo en ese momento una vida corta. Se refunda en mayo de 1919. Poco numerosa, y con poca actividad, se vincula desde 1920 a la Internacional de Trabajadores de la Enseñanza. Apoya el programa educativo elaborado por Lorenzo Luzuriaga en el PSOE.

De las otras dos asociaciones, una parte se vinculó otra vez a la Asociación Nacional del Magisterio. Otros constituyeron asociaciones específicas de maestros, de derechos limitados, que representaban un porcentaje enorme de la

\footnotetext{
${ }^{63}$ Entre las medidas más significativas cabe señalar la incorporación al Estado de los haberes del magisterio en 1901, dependiendo primero de la recaudación municipal y, a partir de 1911, el propio Estado libraba directamente los créditos necesarios. La creación de la Dirección General de Primera Enseñanza en 1911 y la regulación del Estatuto del Magisterio en 1917, y modificado en 1918 y 1923 , son otras de las novedades que se han ido incorporando para mejorar la situación de los maestros en las dos primeras décadas de siglo.

${ }^{64}$ Terrón, A. 1987. «El movimiento asociacionista del Magisterio Nacional. Orígenes y configuración histórica». Historia de la Educación. Revista interuniversitaria 6: 279-299.
} 
plantilla total del magisterio. Es el caso de los interinos y sustitutos, situaciones complejas que tienen su origen en la propia Ley Moyano. En 1918, de una plantilla total de 27.533 maestros, 12.853 pertenecen a este grupo de situación especial. ${ }^{65}$

En este ambiente, se creó en 1912 la Federación Católica de Maestros, que participa, además, del incipiente movimiento de asociacionismo católico del momento. En este proyecto de unir a los maestros católicos toma la iniciativa la asociación madrileña de maestros «La Enseñanza Católica». ${ }^{66}$ A través de la revista de esta asociación, que lleva su mismo nombre, Pedro Poveda promueve la Federación Católica de Maestros. ${ }^{67}$ La respuesta de diversas asociaciones y maestros a esta iniciativa es rápida y numerosa y, además encuentra un especial apoyo en el cardenal Aguirre, primado de Toledo ${ }^{68}$ que, como hemos visto anteriormente, animaba a los católicos a ingresar en el profesorado oficial ${ }^{69}$

La unión de los maestros católicos es uno de los objetivos de un proyecto más amplio que en esos momentos concibe Pedro Poveda e intenta llevar a cabo: la creación de la Institución Católica de Enseñanza. ${ }^{70}$

Unos años más tarde, en 1918, un grupo de profesoras de Escuela Normal e Inspectoras de primera enseñanza de la Institución Teresiana comienza a impulsar la Asociación de Cooperadoras Técnicas de la Institución Teresiana. La conexión con compañeras, procedentes, en general, de la Escuela de Estudios Superiores del Magisterio, es su primer motor de crecimiento. En el Reglamento, aprobado en $1921,{ }^{71}$ aparecen ya los rasgos de identidad que configuran la peculiaridad de esta Asociación:

- Asociadas: mujeres católicas que ejercen algún cargo en la enseñanza oficial o privada. ${ }^{72}$

${ }^{65}$ Idem.

${ }^{66}$ En 1911 esta asociación había realizado una de sus actuaciones más significativas. Hizo de cauce para la unión de fuerzas de la educación católica elaborando una respuesta colectiva al Cuestionario de la «Asamblea General de Enseñanza y Educación», convocada en 1910 por Altamira, Director General de Primera Enseñanza, con el objetivo de discutir y proponer las reformas necesarias en educación. Cfr. García Regidor, T. 1985. La polémica sobre la secularización de la enseñanza en España (1902-1914): 263-268. Madrid: Fundación Santa María.

${ }^{67}$ Velázquez, F. P. 1987: 90-94.

${ }^{68}$ Gómez Molleda, M. D. 1981. Los reformadores de la España contemporánea: 477. Madrid: C.S.I.C.

${ }^{69}$ Ver nota 18.

${ }^{70}$ Véase más arriba lo dicho sobre los orígenes de la Institución Teresiana.

${ }^{71}$ Presentada la solicitud a la Dirección General de Primera enseñanza fue aprobada como Asociación profesional por una R.O. el 7 de junio de 1921. AHIT.

${ }^{72} \mathrm{La}$ situación profesional de las asociadas es uno de los temas más discutidos. Se decide que sean, principalmente, profesoras de Escuelas Normal o Inspectoras de Primera enseñanza, ya que las maestras pueden pertenecer a la Federación Católica del Magisterio. La realidad es que hasta 1929 en que 
- Fines: de carácter religioso, social y científico y profesional.

- Medios: agrupar y organizar las fuerzas católicas profesionales femeninas para la defensa de la fe en la Escuela, estudiar los problemas de la enseñanza y favorecer el intercambio, y crear un Secretariado en Madrid que se encargue de informar de todas las consultas que de índole profesional y administrativa le dirijan las asociadas, así como de aspectos organizativos.

La procedencia mayoritaria de la Escuela de Estudios Superiores del Magisterio facilita la conexión y los puntos de encuentro. Este centro creado en 1909 en ambiente institucionista ${ }^{73}$ es el punto de confluencia de los profesionales de élite de la educación en esos años. No se puede olvidar que es el primer centro español de estudios superiores en educación. ${ }^{74}$ Esta coincidencia facilita otra de las aportaciones específicas de la Institución Teresiana: su encuentro con otras tendencias en propuestas educativas innovadoras desde una postura cristiana. La propia Escuela, caracterizada por el pluralismo ideológico entre sus profesores, ${ }^{75}$ facilitaba diálogos y debates en los que se llegaba a «una conformidad, a veces más presentida que expresada, en los principios en los que asentar la enseñanza y la pedagogía como ciencia». ${ }^{76}$ La mayoría de las cooperadoras técnicas pertenecen, a la vez, a la Asociación Nacional del profesorado numerario de Escuelas Normales.

En agosto de 1922, en San Sebastián, la naciente asociación ya puede celebrar una Asamblea con cierta entidad. ${ }^{77}$ Participaron activamente 50 profesoras e Inspectoras y otras tantas manifestaron su adhesión. Las asistentes proceden de 34 Escuelas Normales distribuidas por las distintas capitales de provincia. Discutieron sobre organización e identidad para hacer efectivo el Reglamento aprobado un año antes. En este momento se consolidó la Asociación. Comenza-

se decide la incorporación de maestras, la Asociación se identifica con las profesoras de Normal e Inspectoras y las actividades que realizan en este periodo se corresponden con esta situación profesional.

${ }^{73}$ Como en otras iniciativas del Ministerio de Instrucción Pública de esos años, es notoria la influencia de la Institución Libre de Enseñanza.

${ }^{74}$ Un estudio sobre este centro, su organización, profesorado, alumnos y aportación innovadora a la educación española es la obra Molero Pintado, A. y del Pozo Andrés, M. M. (ed.), 1989. Un precedente histórico en la Formación Universitaria del Profesorado Español. Escuela de Estudios Superiores del Magisterio (1909-1932). Madrid: Departamento de Educación de la Universidad de Alcalá de Henares.

${ }^{75}$ Convivieron hombres de la Institución Libre de Enseñanza con representantes de la pedagogía católica como Domingo Barnés, Luis de Hoyos, Luis de Zulueta, Ortega y Gasset, Rufino Blanco, Juan Zaragüeta... Viñao Frago, A. 1989. «Hombres e ideas en la Escuela de Estudios del Magisterio. Estudio específico del profesorado», en Molero Pintado, A. y del Pozo Andrés, M. M. (ed.). 1989: 148.

${ }^{76}$ Ibídem, 149.

${ }^{77}$ Aunque se habían realizado reuniones anteriores en las que se fue haciendo realidad el proyecto, a partir de ese momento los documentos se refieren siempre a ésta como la I Asamblea de las Cooperadoras Técnicas. Realmente fue la presentación en sociedad. La presencia de personalidades públicas del mundo eclesial y cultural y el eco de la prensa, favoreció la consolidación de la asociación.

Hispania Sacra, LXIV

129, enero-junio 2012, 345-377, ISSN: 0018-215-X, doi: 10.3989/hs.2012.012 
rá con una actividad significativa a partir del curso 1923-1924, en el inicio del régimen de Primo de Rivera y con la participación en el Congreso Nacional de Educación Católica.

La triple finalidad de la asociación: religiosa, pedagógica-profesional y social, sitúa el núcleo de sus actividades y orientaciones. Así lo expresa una de las conclusiones de esta Asamblea:

«Deben ser características de las Cooperadoras Técnicas: a) en el orden religioso, sólida instrucción en las verdades de la fe, argumentos en que se fundan y manera de rebatir las objeciones que contra ella se propongan, valor para confesar y defender esa fe y sólida virtud; $b$ ) en el orden profesional, exactitud y fidelidad en el cumplimiento del deber, sólida formación científica completada y perfeccionada por el estudio constante, respeto a la autoridad, armonía con las compañeras y un gran amor a las alumnas; $c$ ) en el orden social, adaptación en cuanto sea posible al medio ambiente, ejemplaridad en todos los aspectos de la vida y actuación en las obras de acción social más afines a su cargo». ${ }^{78}$

Tiene mucho que ver con la formación ciudadana y con el papel de los seglares católicos en un contexto cada vez más secularizado, especialmente agudo en España en el primer tercio del siglo XX, cuando «se sacralizó lo laico, se crearon muchos absolutos». Significó un «proceso especialmente duro y agresivo», y con críticas abrumadoras a la Iglesia y a la religión. ${ }^{79}$

Importaba entonces la participación activa de los católicos en la sociedad. Estos tienen que hacerse visibles y hacerse oír. La organización, los criterios claros y la formación para todo esto son imprescindibles. Había que capacitarse para participar en la vida política y social. En este caso, en los ambientes en los que se desarrolla un aspecto fundamental de la educación: la formación de maestras y su seguimiento profesional por medio de la Inspección de Primera Enseñanza.

Otras conclusiones de la Asamblea se refieren a las prioridades del momento: participación en otras Asociaciones, promover la formación de Asociaciones de padres de familia para la «defensa de sus derechos con relación a la enseñanza de sus hijos» y la actuación ante el problema feminista que adoptaba tonos muy radicales.

El profesor Molero Pintado en su estudio sobre la Escuela de Estudios Superiores del Magisterio y su entorno histórico y educativo, destaca de este centro su «vinculación indirecta a la Institución Teresiana». Justifica esta afirmación en el hecho de que Josefa Segovia hubiera sido alumna de la tercera promoción y, en el periodo que nos ocupamos aquí, Directora General de la Institución Te-

\footnotetext{
${ }^{78}$ Carta circular informativa de la Asamblea, Madrid, (1/10/1922). AHIT.

${ }^{79}$ Gómez Molleda, M. D. 2008. Cristianos en la sociedad laica. Una lectura de los escritos espirituales de Pedro Poveda. Madrid: Narcea, 15.
} 
resiana ${ }^{80}$ Lo ya dicho más arriba sobre las Cooperadoras Técnicas adelanta que la conexión es mayor.

Muchas asociadas han asistido a las aulas de la Escuela Superior del Magisterio y, como la mayoría de sus compañeros de estudios, han adquirido una preparación sólida, científica y pedagógica. Se sienten vocacionadas a realizar en las Escuelas Normales, en las que muchas de ellas ejercen la profesión, una proyección de esa preparación. El interés por la formación del magisterio y la innovación educativa en la escuela primaria española es compartido por quienes sienten en sus manos la responsabilidad de regenerar España por la educación, aún partiendo de posturas divergentes. ${ }^{81}$

Entre las que tomaron parte más activa en la asociación podemos nombrar a Carmen Cuesta del Muro, que ocupó primero el puesto de Secretaria y más tarde el de Presidenta. A ella se debe gran parte de la actividad llevada a cabo por las Cooperadoras hasta 1931. Con ella, Antonieta Freixá, Directora de la Normal de Tarragona, Magdalena Martín Ayuso, profesora de la Normal de Teruel, Mariana Ruiz Vallecillo, Inspectora de Primera enseñanza, Pilar Bris, profesora de la Normal de Albacete, María Díaz Jiménez, profesora de la Normal de León, Julia Ochoa, profesora de la Normal de Cuenca, Eloisa de Felipe, Directora de la Normal de Valladolid, Carmen de la Vega Montenegro, profesora de la Normal de Santander, María Ana Sanz, Directora de la Normal de Navarra, Victoria Montiel, Directora de la Normal de Jaén, y Teresa Azpiazu Directora de la Normal de Málaga, coordinadas con otras compañeras suyas y que llevan a cabo una labor de impulso educativo y de promoción cultural en sus ciudades.

El comienzo del curso 1923-24 es especialmente activo. Desde unos meses antes se venía preparando la participación en el I Congreso Nacional de Educación Católica como hemos recogido en páginas anteriores. Desde el Secretariado de la Institución Teresiana ${ }^{82}$ se anima a las asociadas a que envíen memorias a los distintos temas propuestos por las Secciones de Congreso.

Por otra parte, a través de la prensa se conoce que el Directorio militar pide opiniones para una reforma de la enseñanza, y distintos grupos se movilizan con el fin de hacer llegar sus demandas y opiniones ${ }^{83}$ La directiva de la Asociación se hace eco de esta demanda, pero considerando que el plazo para el envío de escritos era muy breve y que el tema requería una reflexión más profunda, decidió no presentar en ese momento ninguna propuesta si no había sido reflexionada y

\footnotetext{
${ }^{80}$ Molero Pintado, A. y del Pozo Andrés, M. M. (ed.). 1989: 35-36.

${ }^{81}$ del Pozo Andrés, M. M. 1989. «La innovación metodológica y la formación del profesorado en la Escuela de Estudios Superiores del Magisterio» en Molero Pintado, A. y del Pozo Andrés, M. M. (ed.) 1989: 65-122.

${ }^{82}$ El Secretariado General de la Institución Teresiana tenía como finalidad la información y conexión de todas las actividades llevadas a cabo por los distintos centros y personas. Actuaba también como oficina de información y orientación en aspectos de legislación y educativos en general.

${ }^{83}$ Véase El Debate de los días 6, 10 y 14 del mes de octubre de 1923.
} 
discutida en Asamblea previamente. ${ }^{84}$ Un año después, finalizado ya el Congreso de Educación Católica, se inició la preparación de una Asamblea en la que se estudiaran y discutieran unos programas para los estudios de Magisterio. ${ }^{85}$

La Asamblea se celebró en Burgos en el verano de 1925. Resultó ser un «Seminario pedagógico» en el que las 69 participantes, agrupadas en las áreas de ciencias, letras y pedagogía, presentaron ponencias para cada una de las materias de la carrera. Las discutieron por secciones y se llevaron a sesiones plenarias. Los programas de las asignaturas habían ido llegando previamente a la organización, para que cada sección pudiera hacer un análisis completo. Se había acordado que cada asociada realizara el estudio de su asignatura recogiendo todo el material posible de España y de otros países.

Este trabajo dio como resultado la redacción de un «Proyecto de reforma del plan de estudios de las Escuelas Normales» que se presentó en febrero de 1926 a Eduardo Callejo de la Cuesta, ministro de Instrucción Pública. ${ }^{86}$

La necesidad de una reforma en las Escuelas Normales se venía planteando entre los profesionales de estos centros desde unos años antes. El plan vigente en ese momento era el de 1914. Este había supuesto un gran avance respecto a la preparación anterior del maestro, pero ya era considerado por la mayoría de los profesores deficitario en los tres aspectos fundamentales: formación cultural, formación pedagógica, y prácticas de enseñanza. ${ }^{87}$

La Asociación Nacional del profesorado numerario de Escuelas Normales venía trabajando en este tema y bastantes páginas de su publicación, la Revista de Escuelas Normales, durante estos años se ocupan con esta cuestión. ${ }^{88}$

Conforme avanza el periodo de la Dictadura se acentúa la urgencia de esta necesidad. Es conocido el aumento importante en el número de escuelas y maestros en este período. Faltaba mejorar la calidad y el nivel de la enseñanza primaria y, para esto, la preparación cultural y profesional de los maestros es clave.

${ }^{84}$ Circular firmada por Carmen Cuesta fechada el 14 de octubre de 1923. AHIT.

${ }^{85}$ Circular de 21 de julio de 1924. AHIT.

${ }^{86}$ Asociación de Cooperadoras Técnicas de la Institución Teresiana. 1926. Texto del «Proyecto de Reforma del Plan de Estudios de Escuelas Normales» presentado al Excmo. Sr. Ministro de Instrucción Pública el día 17 de febrero de 1926. Madrid: Tipografía de A. Alonso.

${ }^{87}$ Sobre la formación de los maestros en este período y el análisis de los distintos planes de estudios lo hemos escrito ya en otro lugar: Peralta Ortiz, M. D. 1988. «Los antecedentes de los estudios universitarios del magisterio. Influencia del Plan de 1931». Tendencias Pedagógicas. $\mathrm{n}^{\circ}$ extraordinario: 201-212, y Peralta Ortiz, M. D. 2000. «Los proyectos sobre los estudios de magisterio en los comienzos del franquismo», Bordón 52-1: 69-86.

${ }^{88}$ No hay que olvidar que Rodolfo Llopis dirigió durante bastante tiempo esta revista y tuvo un papel muy activo en la Asociación Nacional. Iniciada la II República, como Director General de primera enseñanza diseña el conocido como Plan Profesional del Magisterio. El primer antecedente de unos estudios universitarios para la titulación de maestro. 
En el Plan trabajado y discutido y, finalmente enviado al Ministerio, la propuesta de la Institución Teresiana responde a unas líneas directrices que se sintetizan en los siguientes puntos:

- transformación de las Escuelas Normales en Escuelas Profesionales en las que se preparen, además de maestras, profesoras de música, de arte, profesoras mercantiles, etc., y se eleve el nivel cultural;

- colocación directa de las alumnas al terminar sus estudios. Aunque comprenden que aplicando esta medida se pueden plantear problemas económicos, de número de alumnas ${ }^{89} \mathrm{y}$ otros de tipo administrativo y organizativo. Por este motivo envían dos modelos, según se contemple este aspecto o no;

- la duración de la carrera se amplía de cuatro a seis años, de los cuales los dos últimos son específicos de formación profesional, y aumentan considerablemente las materias pedagógicas y el período de prácticas y

— la permanencia de las Normales femeninas.

Existe desde hace años una propuesta de reforma que incluye la fusión de las escuelas normales de maestros y maestras, y que se ha discutido varias veces en las asambleas de la Asociación Nacional. Las Cooperadoras argumentan que suprimir las escuelas normales femeninas supone «tanto como cegar las fuentes de cultura de la mujer, y cerrarle los caminos para que se desenvuelva en la vida». Se necesita una en cada capital de provincia, dicen, y aún es poco. ${ }^{90}$

Otro de los temas discutidos en la Asamblea de Burgos, muy relacionado con la reflexión en torno a un plan de estudios, fue acerca de la conveniencia o no de la implantación de un cuestionario único.

A lo largo del curso 1923-1924 ha ido creciendo la convicción de que el Gobierno podría adoptar la decisión de establecer el cuestionario único para cada asignatura. En febrero de 1924 Primo de Rivera, en un discurso, insiste en el texto único. ${ }^{91}$ A partir de ese momento, la directiva de la Asociación pide a las Cooperadoras que den a conocer su opinión. ${ }^{92}$

\footnotetext{
${ }^{89}$ La selección se haría para ingresar, antes de iniciar los estudios, y el número de matrículas no podía ser superior al de vacantes de escuelas.

${ }^{90}$ Asociación de Cooperadoras Técnicas de la Institución Teresiana. 1926: 6.

${ }^{91}$ López Martín, R. 1995. Ideología y Educación en la Dictadura de primo de Rivera (II) Institutos y Universidades, Valencia: Universitat de València, 93-99. Es claro que la imposición, por parte del Estado, de un libro de texto único para el estudio de cada asignatura, va más allá de lo que supone un mismo cuestionario (programa amplio y detallado). Razonablemente se empezaría por éste último mientras se elaboraba el libro que requería un espacio mayor de tiempo.

${ }^{92}$ La circular de 2 de febrero de 1925 expresa así la importancia del tema: «Recordamos a nuestras compañeras la necesidad de concurrir todas a la misma [Asamblea] con sus programas, para dar base a una amplia y acertada discusión. Tengan presente que Primo de Rivera ha insistido en uno de sus
} 
Es un tema que resulta evidentemente espinoso. Desde una postura liberal va contra la libertad de cátedra y, desde una postura católica podría, si el Estado se sobrepasa, no respetar la libertad educativa defendida desde el principio de subsidiariedad, que reserva para el individuo, la familia y la sociedad lo que ellos pueden llevar a cabo por sus propios medios. ${ }^{93}$

La Asamblea de Cooperadoras lo trata en todas las sesiones. Eso refleja la falta de claridad, al menos en un primer momento, ${ }^{94}$ aunque, enseguida, la Asamblea se va a decantar por la libertad frente a la imposición de un cuestionario. En la primera sesión, la ponente de Pedagogía, Antonieta Freixá presenta las conclusiones de su sección. En la sala se abre el debate sobre la primera de ellas:

« $1{ }^{\text {a }}$ Sobre el cuestionario único, que es la primera cuestión que se presenta, se determina: El cuestionario único, en general, no se cree oportuno, porque si es muy amplio no remedia ninguna necesidad, y si es muy detallado, coacciona y además, en la asignatura de pedagogía puede imponer una determinada tendencia al profesor...». ${ }^{95}$

En otra de las sesiones la misma idea se expresa así:

«Entendiendo que el cuestionario único sólo podría tener la ventaja nominal de unificar la extensión de las materias, aceptarlo sólo en caso de imposición, pidiendo previa consulta al profesorado en cuanto a su contenido y extensión». ${ }^{96}$

Los frutos de esta Asamblea se aprecian, por una parte, en la elaboración y presentación del Plan de Estudios para las Escuelas Normales Femeninas, y por otra, en el avance, que supuso para este grupo, la elaboración de un pensamiento con criterios, que desde una perspectiva cristiana, permitía participar en el debate público sobre cuestiones educativas del momento. Así entendían estas mujeres, profesionales de la educación con cargos muy significativos en ese momento, el desempeño de su actividad, con una dimensión pública y como parte esencial de su catolicismo.

últimos discursos sobre el texto único y hay que prevenirse para hacer las cosas lo mejor posible (Nos alegraría conocer la opinión de nuestras Cooperadoras en ese punto concreto del texto único)».

${ }_{93}^{93}$ Este principio, de la filosofía clásica cristiana, es aplicado a los aspectos sociales y políticos por la incipiente doctrina social de la Iglesia. León XIII en su encíclica Rerum Novarum acude a él para argumentar los límites en la actuación del Estado con respecto a la vida económica, ya antes, en Libertas había hecho lo propio al tratar el tema político. Pero se debe a Pío XI la consagración de la subsidiariedad como uno de los principios «pilares» de la doctrina social de la Iglesia en el $\mathrm{n}^{\circ} 79$ de su encíclica Quadragesimo Anno, de 1931, en el momento de los totalitarismos europeos.

${ }^{94}$ Es explicable. Si se quiere elevar el nivel de la enseñanza, un medio eficaz es hacer obligatorio, y para todos, un cuestionario que defina con claridad el alcance de los aprendizajes de los alumnos. Lo mismo se podría conseguir con un texto único y, además evitaría los abusos de algunos profesores al intentar imponer el suyo. Sin embargo, choca con el principio de la libertad. No es de extrañar tampoco, que esta medida sea contemplada en sistemas intervencionistas.

${ }^{95}$ Diario de Asambleas de Cooperadoras. Acta del día 10 de agosto de 1925. AHIT.

${ }^{96}$ Diario de Asambleas de Cooperadoras. Acta del día 14 de agosto de 1925. AHIT. 
LAS MUJERES DE LA INSTITUCiÓN TERESIANA EN EL ÁMBITO SOCIAL Y PÚBLICO: CONCEJALAS Y ASAMBLEÍSTAS

Primo de Rivera promovió el feminismo de Estado al abrir la puerta a las mujeres en los puestos públicos, inicialmente en las concejalías y después en la Asamblea Nacional. Creía que las mujeres llevarían a la vida pública moderación, responsabilidad y equilibrio. ${ }^{97}$

El Estatuto Municipal de 1924 daba la posibilidad a las mujeres de ser elegidas concejales con las mismas condiciones que se pedía a los hombres, excepto el de la edad. El único requisito añadido para ellas era el de ser mayor de 25 años, mientras que los varones podían ser elegidos a partir de los 23 . Contemplaba, además, por primera vez, el voto de la mujer, aunque restringiéndolo a las cabeza de familia, no sujetas a la patria potestad marital ni tutela y que fueran vecinas en casa abierta. ${ }^{98}$

Un buen número de las mujeres concejalas, que ocuparon el cargo por la aplicación de esta disposición, estaban relacionadas con la educación. Pertenecientes a la Institución Teresiana conocemos a Josefina Olóriz, Ayuntamiento de San Sebastián, Julia Ochoa, Ayuntamiento de Cuenca, Magdalena Martín Ayuso, Ayuntamiento de Teruel, Maria de Echarri, Ayuntamiento de Madrid, Teresa Azpiazu, Ayuntamiento de Málaga, y Catalina García-Trejo, Ayuntamiento de Alicante. Todas, excepto María de Echarri, procedían de la educación. ${ }^{99}$ De algunas de ellas sabemos de sus expectativas y aportaciones a las políticas municipales, al menos indirectamente, pues se conocen sus puntos de interés y preocupaciones.

Magdalena Martín Ayuso permaneció poco más de un año en este cargo. Su preocupación por la educación social y cívica de la mujer mantiene los viejos «clichés». La esfera de acción de la mujer es la familia, aunque la considera muy apta «aportando su cooperación a la obra social y tomando parte en el difícil asunto del gobierno de la Nación». ${ }^{100}$

${ }^{97}$ Ben-Ami, S. 1984. La dictadura de Primo de Rivera 1923-1930: 153-154. Barcelona: Planeta.

${ }^{98}$ Para el seguimiento de este tema véase Díaz Fernández, P. 2005. «La Dictadura de Primo de Rivera. Una oportunidad para la mujer», Espacio, tiempo y forma, Serie V, Historia Contemporánea, t. 17: 180-181. También del Moral Vargas, M. 2007. «Discursos acerca de la presencia de las mujeres en el poder municipal: España 1906-1924», en Aldunate León, O. y Heredia Urzáiz, I. (coord.) Comunicaciones del Primer Encuentro de Jóvenes Investigadores en Historia Contemporánea de la AHC. Zaragoza: Universidad de Zaragoza.

${ }^{99}$ Josefina Olóriz Arcellús, Profesora Auxiliar de la Escuela Normal de San Sebastián. En 1929 Inspectora de Primera Enseñanza; Julia Ochoa Vicente, Profesora de la Escuela Normal de Cuenca; Magdalena Martín Ayuso, Profesora de la Escuela Normal de Teruel; María de Echarri Martinez, Publicista y fundadora del Sindicato de la Inmaculada, Madrid; Teresa Azpiazu, Directora de la Escuela Normal de Málaga y Catalina García Trejo, Auxiliar de la Normal de Alicante.

${ }^{100}$ De su trabajo «Educación cívica y social de la mujer» presentado en el Primer Congreso Nacional de Educación Católica» publicado en BIT, n 122 , enero 1925, 50-52.

Hispania Sacra, LXIV

129, enero-junio 2012, 345-377, ISSN: 0018-215-X, doi: 10.3989/hs.2012.012 
Julia Ochoa Vicente, en sus escritos planteó posiciones más avanzadas. La misión de la mujer no acaba con su tarea de esposa y madre, porque «es tanto lo que en la sociedad hay que mejorar que (...) no se puede prescindir de su acción fuera de la familia».

Después de afirmar el interés de la educación cívica de las niñas en la escuela, insiste en que a la salida de ésta se les debe «preparar para la maternidad con nociones de puericultura, Pedagogía, Economía doméstica e higiene». Sin que esto sea suficiente «muchas, muchísimas jóvenes no están destinadas al matrimonio y (...) hay que inculcarles (...) la necesidad de conseguir su independencia económica».

La educación se centrará en «la necesidad de trabajar los derechos civiles que hoy injustamente se le niegan, principalmente en su condición de esposa y madre».

Y, por último «las prestaciones personales», porque «la mujer que tiene convicciones arraigadas, las expresa con naturalidad cuando la ocasión se presenta». ${ }^{101}$

Josefina Olóriz, nació en Argentina, de ascendiente vasco. Encontramos su pensamiento sobre el papel de la mujer en la ponencia que desarrolló en la III Asamblea de la Asociación de Cooperadoras Técnicas, celebrada en 1929 en Sevilla con el título Posición de las Cooperadoras Técnicas frente a los derechos civiles y políticos de la mujer. Como otras mujeres católicas, sabe que la mujer no había reivindicado los derechos políticos porque en el Código civil «subsisten aún disposiciones ofensivas para la personalidad femenina», tal como también defendía Carmen Cuesta ${ }^{102}$ en el Congreso Hispanoamericano de Acción Católica de la Mujer celebrado en Sevilla ese mismo año. ${ }^{103}$

En esta ponencia, basándose en su propia experiencia municipal insistirá en el papel de la mujer en varios aspectos. La Enseñanza si bien «son pocos los que prácticamente lo sienten, menos los que lo estudian y reducidísimo el número de los que procuran soluciones (...) conocemos localidades en España en que las concejales han realizado una verdadera transformación en este aspecto». ${ }^{104}$

Pide Juntas de protección a la infancia, creación de salas-cuna, Gota de Leche, Hospitales, asilos, Casas de maternidad, Preventorios, Sanatorios y Beneficencia escolar... Higiene y sanidad, mejoramiento de costumbres etc.

Le interesa especialmente la actuación de la mujer española, «femenina y católica», en las funciones públicas. Algunos, dice con ironía, dudan de la capa-

\footnotetext{
${ }^{101} B I T, \mathrm{n}^{\circ} 117$, agosto 1924,163 a 166.

${ }^{102}$ Carmen Cuesta no se había planteado la reivindicación de los derechos políticos de la mujer porque consideraba más urgente cambiar el Código Civil.

${ }^{103} B I T, n^{\circ} 179$, octubre $1929,166-168$.

${ }^{104} B I T, \mathrm{n}^{\circ} 180$, noviembre $1929,182$.
} 
cidad de la mujer y la juzgan «ligera», «diremos que no tenemos la exclusiva y que entre el elemento masculino también hay lo suyo». Actuar con «verdadero espíritu de trabajo» con asesoramiento de técnicos, imponiéndose en lo que dice la ley. ${ }^{105}$

Su discurso acababa con una serie de conclusiones relacionadas con el Código civil y otras, animando a que las cooperadoras asistentes se preparasen para ocupar puestos en Ayuntamientos y Corporaciones. ${ }^{106}$

María de Echarri fue nombrada concejala para ejercer su labor de acuerdo con su experiencia previa y sus convicciones católicas. Sus abundantes y variadas actividades e intereses constituían un buen bagaje para el cargo. Como propagandista católica, trata temas como: salario de la mujer casada, salario familiar, sindicalismo católico, subsidio de maternidad, trabajadoras, subsidios familiares, trabajo extradoméstico de las casadas, unidad de las mujeres católicas, voto femenino. ${ }^{107}$ Consiguió, además, que el Ayuntamiento de Madrid retirara las subvenciones a las escuelas laicas y neutras, en 1925. ${ }^{108}$

Primo de Rivera nombró a 13 mujeres para la Asamblea Nacional con actividades afines a su preparación. Fueron elegidas Josefina Olóriz, María de Echarri y Carmen Cuesta, que formaban parte de la Comisión de Educación. ${ }^{109}$

Josefina Olóriz intervino en la sesión plenaria, celebrada el 15 de diciembre de 1928 sobre Presupuestos. ${ }^{110}$ Todas sus enmiendas se relacionan con la enseñanza. Después de alabar la cantidad asignada del presupuesto de educación a la enseñanza primaria, alaba también el criterio prioritario seguido: creación de Escuelas y aumento de Maestros ${ }^{111}$ y manifiesta la necesidad de mejorarla aún más. ${ }^{12}$ Resume el diagnóstico sobre la escuela en «dos enfermedades»: el aislamiento, con respecto a la sociedad y la rutina del quehacer pedagógico.

${ }^{105}$ Ibídem 183.

${ }^{106}$ Prepararse para la administración de los Ayuntamientos «a fin de evitar que personas ajenas o de ideales opuestos los desempeñen». Buscar la orientación en la Iglesia Católica. No hacer política femenina sino administrar con criterio político y social. Actuación dirigida a moralidad, enseñanza, beneficencia.... En caso de duda, la Cooperadora consultará al Prelado. Dada la necesidad de preparar a la mujer para los nuevos derechos y deberes intensificará y perfeccionará la educación cívica de sus alumnas relacionándola con la formación moral y religiosa. Ibídem 184.

${ }^{107}$ Blasco, I. 2003: 421.

${ }^{108}$ Citado por Franco Rubio, G. 1981. La incorporación de la mujer a la administración del Estado, municipios y diputaciones. 1918-1936: 125-128. Madrid: Ministerio de Cultura.

${ }^{109}$ Diario General de la Institución Teresiana, 20 de septiembre 1927.

${ }^{110}$ Asamblea Nacional, Diario de las sesiones 1928 (36) 317-320.

${ }^{111}$ Se reconoce éste como uno de los mayores logros del régimen: la creación de escuelas de enseñanza primaria, en respuesta al déficit mantenido desde comienzos del siglo a la vez que un objetivo político del regeneracionismo.

${ }^{112}$ En este aspecto se puede decir que existe unanimidad entre todos los profesionales de la educación, pertenezcan a la orientación que pertenezcan.

Hispania Sacra, LXIV

129, enero-junio 2012, 345-377, ISSN: 0018-215-X, doi: 10.3989/hs.2012.012 
Para solucionarlos, hay que aumentar la dotación asignada en los presupuestos para material escolar. Es «absurda», dice, la cantidad para iniciar el servicio de adquisición y edición de películas cinematográficas de carácter científico, industrial y artístico. Así mismo, la asignación presupuestaria para Colonias, cantinas y roperos sigue siendo «absurda e insuficiente». Cubrir estas necesidades de carácter social no debe recaer sólo sobre el Estado, pero sí le corresponde la iniciativa y el estímulo de Municipios y particulares. ${ }^{113} \mathrm{Y}$, por último, defendió la necesidad de incrementar los haberes a los profesores auxiliares de Escuelas Normales.

Intervino de nuevo el 21 de marzo de $1929^{114}$ a propósito del Proyecto de Estatuto de la Primera Enseñanza. Habló sobre la formación del maestro, ${ }^{115}$ su preparación cultural y profesional. El proyecto propone la exigencia del bachillerato elemental para iniciar los estudios. Entiende que esto es lo posible, de momento, para elevar el nivel cultural de los maestros. En su propuesta ideal debería mantenerse la línea de continuidad «Escuela Primaria-Escuela Normal», sin pasar por el Instituto. Pero para que esto fuera posible se necesitaría la existencia en España de las escuelas primarias superiores. ${ }^{116}$ Era especialmente importante la excepción contemplada para las Escuelas Normales femeninas, que permite que éstas organicen la preparación cultural necesaria para las alumnas que quieran cursarla en estos centros. Otra posibilidad es el libre acceso a los estudios, con tal de que hayan adquirido esa cultura previa las aspirantes al magisterio.

En segundo lugar, alaba, en el plan de estudios de las Normales, el que contemple a la vez que esta preparación cultural la adecuada preparación profesional. Por último defiende el impulso a las Normales femeninas presente en el dictamen, que considera estos centros «únicos en España, de cultura superior

113 «La vida de esas instituciones asistenciales requiere el ejercicio de virtudes cristianas y ciudadanas» es el argumento que utiliza para decir que no le corresponde sólo al Estado. Principio muy presente en la doctrina social de la Iglesia.

${ }^{114}$ Asamblea Nacional, Diario de las sesiones 1929 (41) 570-571.

${ }^{115}$ La Revista de Escuelas Normales de ese mes informa sobre estas sesiones y la reforma de los estudios del magisterio que aquí se tratan. Corresponde sólo a una parte de lo que sería el Estatuto completo. La reforma de la Primera enseñanza estaba anunciada desde el comienzo del régimen, el proyecto se había enviado a informe de la Asamblea Nacional en noviembre de 1927 (16 meses antes de la celebración de estas sesiones) y sabemos que nunca vio la luz. La reforma de las Escuelas Normales sería una de las primeras realizaciones de la II República. Ver «La reforma de las Normales» en Revista de las Escuelas Normales 1929 (2 y 3) 81-85.

${ }^{116}$ Esta discusión, que en realidad responde a dos visiones sobre la formación de maestros, se volverá a retomar en el primer Ministerio del régimen franquista cuando, en 1938, se proyecte una nueva reforma. Finalmente se concluyó con la ley de 1945 que exigía cuatro años de bachillerato para acceder a los estudios de Magisterio. Algo muy similar a lo que ha propuesto la Asamblea Nacional. Peralta Ortiz, M. D. 2012. La escuela primaria y el magisterio en los comienzos del franquismo. Madrid: Universidad Pontificia Comillas. 
por la mujer y para la mujer», ${ }^{117}$ proporcionando «la formación netamente patriótica, netamente española y netamente cristiana de la mujer».

María de Echarri dedicó gran parte de su labor a los asuntos relacionados con la acción social, la sanidad y la beneficencia. Reclamará mejoras salariales para las maestras y reformas penitenciarias para las mujeres reclusas. Lo hizo el 19 de enero de 1928. María conocía bien la situación de las cárceles porque las visitaba a menudo. ${ }^{118} \mathrm{El}$ estado de los inmuebles destinados a cárceles es lamentable, especialmente en Madrid y Segovia. Es un poco mejor, en Alcalá. La mala situación moral de las presas se debe a que todas las de España están concentradas en dos o tres sitios. Las más inocentes se han «pervertido» en contacto con «las profesionales». Pide que se adopte el sistema celular, una persona, una celda, para evitar esta mala influencia de unas en otras.

Una vez cumplida la pena, «es preciso facilitarles el camino para que puedan regenerarse (...) porque la libertad condicional tendrá plena eficacia cuando el favorecido por ella sepa que puede encontrar un techo bajo el cual cobijarse y un trabajo honesto que le permita defenderse en la vida». Echarri insiste en la necesidad de Patronatos, similares a los que aparecieron en Alemania a finales del XVII para atender a los presos a la salida de la cárcel. Patronatos que han sido transformados con poca fortuna por lo que quiere que se repongan. ${ }^{119}$

Carmen Cuesta del Muro, entre los distintos asuntos que trató, destaca el de los Derechos civiles de la mujer, el 23 de mayo de 1928. Este tema ya había sido objeto de su tesis doctoral defendida en la Universidad de Madrid ese mismo año y publicada posteriormente. ${ }^{120}$

Era una cuestión que venía preocupando a distintos colectivos femeninos desde unos años atrás. Maria Bris, miembro de la primera Junta de la Juventud Católica Femenina y Presidenta de la Confederación Católica Femenina de Estudiantes desde 1924, y Cooperadora Técnica de la Institución Teresiana, decía en el Boletín de la ACM:

«Esta anulación de la mujer, que se observa en el Código Civil, se refleja lo mismo en las relaciones entre los cónyuges que respecto a sus bienes y a las personas de sus hijos». ${ }^{121}$

\footnotetext{
${ }^{117}$ El subrayado es nuestro.

${ }^{118}$ La relación con la Obra postcarcelaria no es solo de Echarri sino algo normal de la Institución. Dice Josefa Segovia «Nos visita Joaquina López de Ayala, fundadora de la obra postcarcelaria» (Diario, 29 de mayo, 1926)

${ }^{119}$ Asamblea Nacional, Diario de las sesiones. Sesión plenaria celebrada el jueves, 19 de enero de $1928,374$.

${ }^{120}$ Cuesta, C. 1930. La sociedad de gananciales. Madrid: Librería de Victorino Suárez.

${ }^{121}$ Bris, M. 1924. «La mujer en el Código Civil», Boletín de la ACM 48: 44-48.
} 
Como Cuesta, reclamaba para la mujer que pudiera administrar y disponer de su propio salario, sin estar obligada a recibir el consentimiento de su marido, como el Código estipulaba, algo que ya la marquesa del Rafal y María de Echarri habían planteado en los debates del Instituto de Reformas sociales.

Carmen Cuesta recorre el Código Civil haciendo ver sus contradicciones. En él, se trata a la mujer con desprecio y extraordinaria desconsideración. El artículo 237 dice que las mujeres no pueden ser tutores ni protutores. La mujer sigue en inferioridad, pues en el Código sólo hay dos clases de mujeres: la soltera y la viuda. Insiste en quitar las restricciones para la mujer y que se le conceda la misma mayoría de edad que el hombre. No puede salir de casa sino es «para tomar estado», y no se considera estado más que el matrimonio. Debe suprimirse la prohibición de que no sean testigos en testamentos, excepto en caso de epidemia. La mujer casada ha de recobrar la plena capacidad jurídica en los casos de separación legal, deberá conservar la patria potestad sobre sus hijos aunque contraiga nuevas nupcias. No está de acuerdo en que sólo el marido maneje los bienes gananciales sin consentimiento de su mujer. Propuso nueve bases en las que resumía sus peticiones para que fueran tenidas en cuenta por el legislador.

El Ministro de Gracia y Justicia, Galo Ponte Escartín, reconoce sus apreciaciones y, con ironía insiste: «lo que la Srta. Cuesta pretende en su interpelación de hoy, es la enmienda, no de un artículo, sino de todo el Código civil. ${ }^{122}$

Posiblemente la petición de Cuesta era muy ambiciosa para un Régimen que, inicialmente, se consideraba transitorio. El Código Civil español, basado en el francés de 1804, que perpetuaba un modelo femenino caracterizado «por su extrema fragilidad psicológica e intelectual y su absoluta incapacidad de entender y actuar autónomamente, estaba obsoleto. ${ }^{123}$ Los cambios efectuados por la Constitución de 1931, dada la convulsa situación republicana y la Guerra Civil, no se estabilizaron hasta la Ley del 24 de abril de $1958 .{ }^{124}$ Posteriormente destacó, en este sentido, la actividad de María Telo Núñez y la Asociación Española de Mujeres Juristas que contribuyeron a las principales reformas legislativas. ${ }^{125}$

Carmen Cuesta, en el debate sobre presupuestos, insiste en que se contemplen fondos para la creación de Institutos femeninos; para la Universidad femenina, sobre todo de Medicina; creación de nuevas Escuelas Normales e incremento

\footnotetext{
${ }^{122}$ Asamblea Nacional, Diario de las sesiones, 23 de mayo de 1928, 881-882.

${ }^{123}$ Di Febo, G. 1979. Resistencia y movimiento de mujeres en España, 1936-1975. Barcelona: Icaria, 130 .

${ }^{124}$ Relacionada con la campaña levantada por Mercedes Formica desde 1950 que trasladó la problemática de la mujer a la situación jurídica y social de las mujeres españolas de esos años, dada su colaboración con $A B C$ donde el 7 de noviembre publicó su artículo «El domicilio conyugal» en que narraba cómo Antonia Pernia había recibido once puñaladas de su marido. Este hecho sirvió a Formica para señalar la discriminación que, por razón de sexo, sufría la mujer española.

${ }^{125}$ Ruíz Franco, R. 2007. ¿Eternas menores? Las mujeres en el franquismo. Madrid: Biblioteca nueva.
} 
de Inspecciones; aumento del profesorado numerario femenino en las Escuelas Normales, y mejora de sueldos del profesorado auxiliar de las Escuelas Normales. Incluso llega a pedir que se paralizase la construcción de edificios escolares con el fin de poder aumentar el sueldo de los maestros. Pide también aumento de sueldo para las porteras y conserjes de las Escuelas Normales femeninas. ${ }^{126}$

Cuando el 15 de febrero de 1930 es disuelta la Asamblea, de las 13 mujeres que han formado parte de la misma, puede decirse que «todas ellas trataron de llevar a debate, de forma seria y estudiada aquellos problemas que consideraban más importantes para la mujer en su momento». ${ }^{127}$

\section{A MODO DE CONCLUSIONES}

Cuando Baldomero Jiménez Duque hace una síntesis de los católicos españoles en el XIX y principios del XX, utiliza tres adjetivos calificativos: activos, prácticos y románticos. Hemos aplicado igualmente a las mujeres del catolicismo social de los años 20 estos calificativos. El simple repaso a lo dicho anteriormente lo avala.

Fueron activas. Las mujeres se movilizaron desde todos los sectores sociales, y especialmente de la burguesía, en el proyecto político del catolicismo español a través de la educación, de un modo nada convencional. ${ }^{128}$

Fueron prácticas. No sólo promovieron y protagonizaron el acceso al espacio público, sino que reclamaron su participación política, articulando las demandas de inclusión alrededor de las nociones católicas de género, religión y patriotismo. La proyección fuera del hogar y su vínculo con la Religión les llevaba a entrar en la esfera pública para recristianizarla. Sus posibilidades fueron el patriotismo, la mayor religiosidad y las cualidades femeninas. Los discursos de Echarri, Olóriz, Ochoa, Ayuso, incluso el de Carmen Cuesta y su «desinterés» por el sufragio, deben contextualizarse adecuadamente.

Fueron románticas. Sentían el deber de salvar a España, al catolicismo, a la educación... en nombre de Dios, ciertamente. Sus escritos y sus palabras descubren su percepción y su juicio sobre el anticlericalismo y sus homólogos: laicismo, masonería, neutralidad... eran el caos, la destrucción de las personas y de la nación, de los individuos y de la sociedad.

\footnotetext{
${ }^{126}$ Asamblea Nacional, Diario de las sesiones, 11 de diciembre de 1928. Apéndice al no 32, 2.

${ }^{127}$ Díaz Fernández, P. 2005: 187.

${ }^{128}$ «El acceso a la enseñanza secundaria e incluso superior, el activismo constante, las responsabilidades organizativas, los viajes frecuentes, el uso de la palabra en público y de la escritura en revistas y periódicos no formaban parte...de la experiencia de la mayoría de las mujeres españolas en su momento», Blasco, I. 2003: 286. 
Esta fue la confrontación entre confesionalidad y laicismo. «La única forma de quebrar el peso del tradicionalismo, del integrismo religioso, era la ya repetida ruptura con todo lo existente», escribe Suárez Cortina. Una batalla que se dirimía especialmente en la Escuela, como campo de experiencias extraordinario «para conocer registros y procedimientos, pues las escuelas laicas, racionalistas y neutras no fueron sino expresiones y experiencias educativas de una gran corriente que hizo del laicismo en sus diversas gradaciones, su leitmotiv: neutralizar los efectos de la enseñanza confesional». ${ }^{29}$

Este es el mundo y el momento, donde y cuando se desarrolló la pugna por el control de la escuela y en los que la Institución Teresiana fue una punta de lanza, sin que sea tan obvio que unos representaran taxativamente la Tradición y otros la Modernidad.

\section{BiBLIOGRAFÍA}

Primer Congreso Nacional de Educación Católica. Madrid, 21-26 de abril de 1924. 1925. Madrid: Tipografía de la «Revista de Archivos».

AA.VV. 1993. Josefa Segovia. Volumen-homenaje. Primer Centenario de su nacimiento 1891-1957. Madrid: Narcea

Adagio, C. 2004. Chièsa e Nazione in Spagna. La ditatura de Primo de Rivera (19231930). Milano: Unicopli.

Arce Pinedo, R. 2008. Dios, Patria, Hogar. La construcción social de la mujer española por el catolicismo y las derechas en el primer tercio del siglo XX. Santander: Universidad de Cantabria.

Ben-Ami, S. 1984. La dictadura de Primo de Rivera 1923-1930. Barcelona: Planeta.

Blasco, I. 2003. Paradojas de la ortodoxia. Política de masas y militancia católica femenina en España (1919-1939). Zaragoza: Prensas Universitarias de Zaragoza.

Bris, M. 1924. «La mujer en el Código Civil», Boletín de la ACM 48: 44-48.

Callahan, W. J. 2002. La Iglesia católica en España (1875-2002): Barcelona: Crítica.

Cano, L. 2009. Reinaré en España. La mentalidad católica a la llegada de la Segunda República. Madrid: Encuentro.

Capel, R. M. 1986. El trabajo y la educación de la mujer en España 1910-1930. Madrid: Instituto de la Mujer.

Casas, S. 2006. «La Agenda de la Conferencia de Metropolitanos», en Jaime Aurell i Cardona y Pablo Pérez López (eds.). Católicos entre dos guerras. Madrid: Biblioteca nueva.

Cuesta del Muro, C. 1915. La vida y el obrero. Curso de conferencias dadas a los obreros de Madrid. Madrid: Tipografía del Sagrado Corazón.

Cuesta del Muro, C. 1930. La sociedad de gananciales. Madrid: Librería de Victorino Suárez.

\footnotetext{
${ }^{129}$ Suárez Cortina, M. 2002. «Democracia y anticlericalismo en la crisis de 1898» en Aubert, P. (ed.), Religión y sociedad en España (siglos XIX y XX): 179-218. Madrid: Casa de Velázquez.
} 
Di Febo, G. 1979. Resistencia y movimiento de mujeres en España, 1936-1975. Barcelona: Icaria.

Díaz Fernández, P. 2005. «La Dictadura de Primo de Rivera. Una oportunidad para la mujer», Espacio, tiempo y forma, Serie V, Historia Contemporánea, t. 17: 180-181.

Flecha García, C. 1988. «La primera Residencia universitaria femenina en España», en A.A. V.V., Pedro Poveda, Volumen-Homenaje cincuentenario 1936-1986: 321-335. Madrid: Narcea.

Flecha García, C. 1999. Las primeras universitarias españolas. Madrid: Narcea.

Franco Rubio, G. 1981. La incorporación de la mujer a la administración del Estado, municipios y diputaciones. 1918-1936. Madrid: Ministerio de Cultura.

Fullana, P. y Ostolaza, M. 2007. «Escuela católica y modernización. Las nuevas congregaciones religiosas en España (1900-1930)», en de la Cueva, J. y Montero, F. (eds.), La secularización conflictiva. España (1898-1931): 187-213. Madrid: Biblioteca Nueva.

Galino, A. 1964. P Poveda. Itinerario Pedagógico. Madrid: C.S.I.C.

Gallego, A. y Pazos, J. A. 1999. La Iglesia en la España contemporánea. 1800-1936. Madrid: Encuentro.

García Checa, A. 2007. Ideología y práctica de la acción social católica femenina (Cataluña, 1900-1930). Málaga: Universidad de Málaga.

García Hoz, V. 1974. La pedagogía de Pedro Poveda y la formación de educadores. Discurso pronunciado por... en la Sesión conmemorativa en la UNESCO con ocasión del nacimiento de Pedro Poveda. París: UNESCO.

García Regidor, T. 1985. La polémica sobre la secularización de la enseñanza en España (1902-1914). Madrid: Fundación Santa María.

Gómez Molleda, M. D. 1981. Los reformadores de la España contemporánea: 477. Madrid: C.S.I.C.

Gómez Molleda, M. D. 2008. Cristianos en la sociedad laica. Una lectura de los escritos espirituales de Pedro Poveda. Madrid: Narcea.

González Calleja, E. 2005. La España de Primo de Rivera. La modernización autoritaria 1923-1930. Madrid: Alianza.

González, E. 2006. Pasión por la santidad. Biografía de Ma Josefa Segovia, Madrid: B.A.C.

Llopis, R. 2005. La revolución en la escuela: Dos años en la Dirección General de Primera Enseñanza. Edición y estudio introductorio de Antonio Molero Pintado. Madrid: Biblioteca Nueva.

López Martín, R. 1995. Ideología y Educación en la Dictadura de primo de Rivera (II) Institutos y Universidades, Valencia: Universitat de València.

Martí Gilabert, F. 1993. «La Iglesia y la Dictadura de Primo de Rivera». Anuario de Historia de la Iglesia, 2: 151-178.

Molero Pintado, A. y del Pozo Andrés, M. M. (ed.), 1989. Un precedente histórico en la Formación Universitaria del Profesorado Español. Escuela de Estudios Superiores del Magisterio (1909-1932). Madrid: Departamento de Educación de la Universidad de Alcalá de Henares.

Montero, F. 1993. El movimiento católico en España. Madrid: Eudema.

Montero F. (coord.) 2008. La Acción Católica en la Segunda República. Alcalá de Henares: Universidad de Alcalá. 
Montero, M. 2009. La conquista del espacio público: mujeres españolas en la Universidad (1910-1936). Madrid: Minerva.

Moral Vargas, M. 2007. «Discursos acerca de la presencia de las mujeres en el poder municipal: España 1906-1924», en Aldunate León, O. y Heredia Urzáiz, I. (coord.) Comunicaciones del Primer Encuentro de Jóvenes Investigadores en Historia Contemporánea de la AHC. Zaragoza: Universidad de Zaragoza.

Moreno Seco, M. 2005. «Mujeres, clericalismo y asociacionismo católico», en A.A. V.V., Clericalismo y asociacionismo católico en España: de la restauración a la transición: 107-133. Cuenca: Centro de Estudios Castilla-La Mancha.

Paine, S. G. 2006. El catolicismo español: 196. Barcelona: Planeta.

Pego Puigbó, A. 2006. Modernidad y pedagogía en Pedro Poveda. La experiencia de Covadonga. Salamanca: Universidad Pontificia de Salamanca, Cátedra «Pedro Poveda».

Peralta Ortiz, M. D. 1988. «Los antecedentes de los estudios universitarios del magisterio. Influencia del Plan de 1931». Tendencias Pedagógicas. nº extraordinario: 201-212.

Peralta Ortiz, M. D. 2000. «Los proyectos sobre los estudios de magisterio en los comienzos del franquismo», Bordón 52-1: 69-86.

Peralta Ortiz, M. D. 2012. La escuela primaria y el magisterio en los comienzos del franquismo. Madrid: Universidad Pontificia Comillas.

Poveda, P. 2005. Pedro Poveda, Obras I. Creí por esto hablé. Edición crítica y estudio de Gómez Molleda, M. D. Madrid: Narcea.

Reig y Casanova, E. 1926. Principios y bases de la reorganización de la Acción Católica Española, promulgadas por su director pontificio, el Emmo. y Rvdmo. Sr. D. Enrique Reig y Casanova. Toledo: Imprenta de la Editorial Católica Toledana.

Restrepo, F. 1924 «El Congreso de Educación y la Exposición pedagógica». Razón y $\mathrm{Fe}$, 69: 149.

Revuelta González, M. 2005. La Iglesia española en el siglo XIX. Desafíos y respuestas. Madrid: Universidad Pontificia Comillas.

Rosique, F. 1988. «Diálogos de Poveda con la mujer, la figura de María de Echarri», en A.A. V.V., Pedro Poveda, Volumen-Homenaje cincuentenario 1936-1986: 336-354. Madrid: Narcea.

Ruíz Franco, R. 2007. ¿Eternas menores? Las mujeres en el franquismo. Madrid: Biblioteca nueva.

Sanz de Diego, R. M. 1988. «Pedro Poveda, lector de «Razón y fe» en Covadonga», en A.A. V.V., Pedro Poveda, Volumen-Homenaje cincuentenario 1936-1986: 135-160. Madrid: Narcea.

Suárez Cortina, M. 2002. «Democracia y anticlericalismo en la crisis de 1898» en Aubert, P. (ed.), Religión y sociedad en España (siglos XIX y XX): 179-218. Madrid: Casa de Velázquez.

Terrón, A. 1987. «El movimiento asociacionista del Magisterio Nacional. Orígenes y configuración histórica». Historia de la Educación. Revista interuniversitaria 6: 279 a 299.

Velázquez, F. P. 1987. Proyectos pedagógicos. Madrid: Narcea.

Velázquez, F. P. 1996. Las Academias, Madrid: Narcea.

Velázquez, F. P. 2003. Pedro Poveda en Madrid. Madrid: Narcea. 